\title{
DESARROLLO DE LA JURISDICCIÓN \\ INTERNACIONAL 2001-2002
}

La proliferación de tribunales es un fenómeno característico del desarrollo del derecho internacional en el último siglo. La consistencia de la interpelación del derecho puede verse afectada por la diversidad de foros en los que se discute el contenido de las normas internacionales. Teniendo esto en mente, es conveniente acercarse al desarrollo del derecho internacional según es aplicado por los diversos foros competentes. En este texto se presenta en general la situación de la jurisdicción internacional actualmente, y más adelante se discuten los desarrollos de la Corte Internacional de Justicia, el Tribunal Internacional de Derecho del Mar, los casos presentados en el Centro Internacional de Solución de Disputas de Inversión, el desarrollo de la aplicación del capítulo 11 del TLCAN, y la jurisprudencia de la Corte Interamericana de Derechos Humanos.

\section{ANTECEDENTES}

La proliferación de los órganos jurisdiccionales internacionales es una notable característica del desarrollo del derecho internacional en el último siglo, y representa: "Un esfuerzo por mejorar la eficiencia de las obligaciones de derecho internacional público, con el establecimiento de algunos mecanismos convencionales de seguimiento, en particular en el campo de los derechos humanos, derecho económico internacional, derecho comercial internacional y derecho ambiental internacional". ${ }^{1}$

De acuerdo con Cessare Romano ${ }^{2}$ una buena definición de un órgano jurisdiccional es la proporcionada por Christian Tomuschat: a) Debe ser per-

1 Dupuy, P. M., The Danger of Fragmentation or Unification of the International Legal System and the International Court of Justice (1999) 31 NYU J Int'1 L \& Pol 791, 795: “An effort to improve the efficiency of public international obligations, with the establishment of some conventional and sophisticated 'follow-up machineries', in particular in the field o human rights, international economic law, international trade law, and international environmental law".

2 Director asociado del Proyecto de Cortes y Tribunales Internacionales, en el Centro de Cooperación Internacional de la Universidad de Nueva York (Romano, C., The Proliferation of International Judicial Bodies: The Pieces of the Puzzle (1999) 31 NYU J Int'1 L \& Pol 709). 
manente; $b$ ) Debe estar establecido por un instrumento legal internacional; c) Deben decidir los casos llevados ante ellos con base en derecho internacional; $d$ ) Las reglas de procedimiento deben existir ante facto; $e$ ) El resultado debe ser legalmente vinculatorio. ${ }^{3}$ Estos criterios excluyen a tribunales ad hoc que sólo representan un marco institucional estable para el arbitraje y la conciliación. Romano estipula otros dos criterios que podrían no obstante quedar subsumidos en alguna de las anteriores categorías, a saber: $f$ ) Que los jueces no sean ad hoc en su mayoría; y $g$ ) La disputa resultante debe ser entre dos entidades, de las cuales al menos una debe ser un Estado o una organización internacional.

Actualmente hay 16 cuerpos que cumplen con estos requisitos, que llamaré en su conjunto "jurisdicción internacional" (international judiciary). La jurisdicción internacional ha sido clasificada por Romano así:

\begin{tabular}{|c|c|c|c|c|}
\hline JURISDICCIÓN & & TRIBUNAL & VIGENCIA & MIEMBROS $^{5}$ \\
\hline \multirow{2}{*}{$\begin{array}{l}\text { Jurisdicción } \\
\text { general }\end{array}$} & 1 & Corte Internacional de Justicia $^{6}$ & 1945 & 63 \\
\hline & 2 & $\begin{array}{l}\text { Corte Centroamericana } \\
\text { de Justicia }^{7}\end{array}$ & 1994 & 9 \\
\hline $\begin{array}{l}\text { Derecho } \\
\text { del mar }\end{array}$ & 3 & $\begin{array}{l}\text { Tribunal Internacional } \\
\text { de Derecho del Mar }\end{array}$ & 1996 & 16 \\
\hline \multirow{3}{*}{$\begin{array}{l}\text { Derechos } \\
\text { humanos }\end{array}$} & 4 & $\begin{array}{l}\text { Corte Europea de Derechos } \\
\text { Humanos }\end{array}$ & 1958 & 49 \\
\hline & 5 & $\begin{array}{l}\text { Corte Interamericana } \\
\text { de Derechos Humanos }{ }^{10}\end{array}$ & 1979 & 17 \\
\hline & 6 & Corte Penal Internacional ${ }^{11}$ & 2002 & 63 \\
\hline
\end{tabular}

3 Ibidem, pp. 713 y 714.

4 En esta tabla se muestran jurisdicción, vigencia y membresía de tribunales internacionales.

5 Estos datos no incluyen tribunales arbitrales, sino sólo medios estrictamente jurisdiccionales (Cfr.www.pict-pcti.org).

6 Carta de Naciones Unidas, www.un.org.

7 Protocol of Tegucigalpa art. 22.k (1991) 36 ILM 923, que reforma la Carta de la Organización de Estados Centroamericanos (1962) 2 ILM 235.

8 United Nations Convention for the Law of the Sea, art. 287 (1982), NU Doc A/CONF.62/121 (1982) 21 ILM 1982.

9 European Convention for the Protection of Human Rights and Fundamental Freedoms (1950) 213 UNTS 221.

10 American Convention on Human Rights (1969) 1144 UNTS 123.

11 Rome Statute of the International Criminal Court, UN Diplomatic Conference of Plenipotentiaries on the Establishment of an International Criminal Court, July 17, 1998, Annex II, U.N.Doc A/CONF. 183/9 (1998). 


\begin{tabular}{|c|c|c|c|c|}
\hline JURISDICCIÓN & & TRIBUNAL & VIGENCIA & MIEMBROS \\
\hline \multirow{9}{*}{$\begin{array}{l}\text { Órganos de } \\
\text { integración } \\
\text { económica } \\
\text { regional }\end{array}$} & 7 & $\begin{array}{l}\text { Corte de Justicia de las Comunidades } \\
\text { Europeas }\end{array}$ & 1952 & 15 \\
\hline & 8 & $\begin{array}{l}\text { Corte de Primera Instancia de las } \\
\text { Comunidades Europeas }\end{array}$ & 1988 & 15 \\
\hline & 9 & $\begin{array}{l}\text { Corte de la Asociación Europea } \\
\text { de Libre Comercio (EFTA) }\end{array}$ & 1994 & 3 \\
\hline & 10 & $\begin{array}{l}\text { Corte de Justicia de la Unión } \\
\text { Económica Benelux }\end{array}$ & 1974 & 3 \\
\hline & 11 & $\begin{array}{l}\text { Corte de Justicia del Mercado } \\
\text { Común de África Suroriental }\end{array}$ & 1998 & $\mathrm{ND}^{*}$ \\
\hline & 12 & $\begin{array}{l}\text { Corte Común de Justicia y Arbitraje } \\
\text { de la Organización para la } \\
\text { Armonización de Derecho } \\
\text { Corporativo en África }^{17}\end{array}$ & 1997 & 16 \\
\hline & 13 & $\begin{array}{l}\text { Corte de Justicia de la Unión } \\
\text { del Magreb Árabe }\end{array}$ & 1989 & 5 \\
\hline & 14 & $\begin{array}{l}\text { Cuerpo Judicial de la Organización } \\
\text { de Países Exportadores } \\
\text { de Petróleo }\end{array}$ & 1980 & 10 \\
\hline & 15 & $\begin{array}{l}\text { Corte de Justicia de la Comunidad } \\
\text { Andina }^{20}\end{array}$ & 1984 & 5 \\
\hline $\begin{array}{l}\text { Tribunal } \\
\text { naciente }\end{array}$ & 16 & $\begin{array}{l}\text { Corte Africana de Derechos } \\
\text { Humanos y de los Pueblos }\end{array}$ & & ND \\
\hline
\end{tabular}

12 Treaty Establishing the European Coal and Steel Community (1951) 24 UNTS 140; Treaty Establishing the European Economic Community (1957) 298 UNTS 3.

13 Decision of The Council of Ministers, October 24 1988, 1988 OJ (L319) I.

14 Agreement on the European Economic Area (1992) 1795 UNTS 3.

15 Treaty Instituting the Benelux Economic Union, art. 6.3 (1958) 381 UNTS 165.

16 Treaty Establishing the Common Market for Eastern and Southern Africa art. 30 (1993) 33 ILM.

* ND: No disponible.

17 Treaty Establishing the Organization for the Harmonization of Corporate Law in Africa (1993) 4 OJ OHADA.

18 Treaty Instituting the Arab Magreb Union (1989) 94 RGDIP 552.

19 Treaty for the Establishment of an Arab Organization for the Petroleum Exporting Countries (1968) 68 UNTS 255.

20 Tratado que Establece la Corte de Justicia del Pacto de Cartagena, art. 29 (1979) 18 ILM

21 Protocol to the African Charter of Human and People's Rights (1998) 58 ZaöR 727 art. 7. 
La noticia más relevante sobre el desarrollo de la jurisdicción internacional es, este año, la entrada en vigor del Estatuto de Roma de la Corte Penal Internacional que castigará acciones similares a las castigadas en los tribunales ad hoc, pero se diferencia de éstos por ser un tribunal permanente, creado ante facto por un tratado y no por una resolución del Consejo de Seguridad. Preocupa, sin embargo, el retiro de la firma del Estatuto por parte de los Estados Unidos de América el 6 de mayo de 2002. Esto permite al Estado actuar en contra del objeto y propósito del Estatuto, y podría acarrear efectos legales en el caso de que un nacional de ese país sea sujeto a la jurisdicción de la corte. ${ }^{22}$

Es importante también la ampliación del acceso directo de los individuos a la Corte de Primera Instancia de las Comunidades Europeas. En el Caso Jego-Quèrè et Cie ${ }^{23}$ se modificaron los criterios para determinar si un individuo se ve afectado por una norma comunitaria. Normalmente se requería que las peculiaridades de hecho en un caso particular hicieran al individuo más vulnerable a una resolución comunitaria, para que se le concediera acceso a la corte. No obstante, en esta decisión la corte, basándose en la relevancia de la existencia de remedios efectivos como principio constitucional de los Estados miembros, determinó que bastaba con que la medida afecte la posición legal del individuo, restringiendo sus derechos o imponiendo obligaciones de modo inmediato.

La Corte Africana de Derechos Humanos está en proceso de creación (sólo cinco Estados han ratificado el estatuto, y para su entrada en vigor se requieren 15$)^{24}$ y merece un comentario. Es particularmente relevante porque permite la aplicación no sólo de la Convención Africana de Derechos Humanos y de los Pueblos, sino de cualquier tratado de derechos humanos del que el Estado implicado sea parte ${ }^{25}$ y le concede capacidad a las ONG africanas reconocidas por la Organización para la Unidad Africana (OUA) para solicitar consultas a la corte. ${ }^{26}$

22 Press Statement, International Criminal Court: Letter to UN Secretary General Kofi Annan, http://www.state.gov/r/pa/prs/ps/2002/9968.htm.

23 Jego-Quéré et Cie vs. Commission Judgement of the Court of First Instance T-177/07, May 3, 2002 http://curia.eu.int/en/index.htm.

24 Resolution on the Ratification of the Protocol to the African Charter on Human and Peoples' Rights on the Establishment of an African Court on Human and Peoples' Rights, Preotria, May 16, 2002, http://www1.umn.edu/humanrts/africa/courtresolution-2002.html.

25 African Charter of Human and People's Rights, (1998) 58 ZaöR 727 art. 7.

26 Ibidem, art. 4.1. 
Una interpretación más amplia de las condiciones señaladas permitirían añadir a la lista:

1. Tribunal Penal Internacional para la ex-Yugoslavia (1993). ${ }^{27}$

2. Tribunal Penal Internacional para Ruanda (1995). ${ }^{28}$

3. Mecanismo de Resolución de Controversias de la OMC (1995). ${ }^{29}$

Sin embargo, los dos primeros no son permanentes, y el tercero es más similar a un mecanismo arbitral. Además de esta lista, existen actualmente siete comisiones o tribunales permanentes de arbitraje, 11 tribunales administrativos, tres paneles de inspección, y dos comisiones de compensación. ${ }^{30}$

El incremento de los órganos jurisdiccionales internacionales durante el último siglo puede apreciarse en la gráfica de la siguiente página. Se observa que desde la desaparición de la Corte de Justicia Centroamericana en 1918, y hasta la aparición de la Corte de Justicia de las Comunidades Europeas en 1958, en el mundo había un sólo órgano judicial: la Corte Mundial. En la gráfica se aprecia que el más rápido incremento en el número de cuerpos apareció en la última década. Cessare Romano atribuye esto a la reciente regulación internacional de temas que se encontraban en la jurisdicción doméstica de los Estados: "Al ser concebida de esta manera, la proliferación de foros judiciales internacionales se convierte en el precipitado de la creciente densidad normativa del sistema jurídico internacional" ${ }^{31}$ Esto se confirma, por ejemplo, por la acelerada proliferación de tratados internacionales particularmente en la última década. Otros factores que influyeron en este proceso son la caída del 'bipolarismo' con la Unión Soviética, el desuso de las teorías marxistas-leninistas de interpretar las relaciones internacionales y la expansión del modelo de economía de libre mercado. ${ }^{32}$

27 UN S C Res 827 Establishing an International Tribunal for the Prosecution of Persons Responsible for Serious Violations of International Humanitarian Law Committed in the Territory of the Former Yugoslavia 32 ILM 1203 (1993).

28 UN S C Res 55 Establishing the International Tribunal for Rwanda 33 ILM 1598 (1994).

29 General Agreement on Tariffs and Trade: Multilateral Trade Negotiations Final Act Embodying the Results of the Uruguay Round of Trade Negotiations 33 ILM 1125 (1994).

30 Véase cuadro, en Romano, The Proliferation..., cit., nota 2.

31 Ibidem, p. 729: "When conceived in this manner, the multiplication of international judicial fora becomes the precipitate of the accrued normative density of the international legal system" (trad. mía).

32 Ibidem, pp. 729-738. 
GRÁFICA 1. PROLIFERACIÓN DE TRIBUNALES INTERNACIONALES 1909-2002

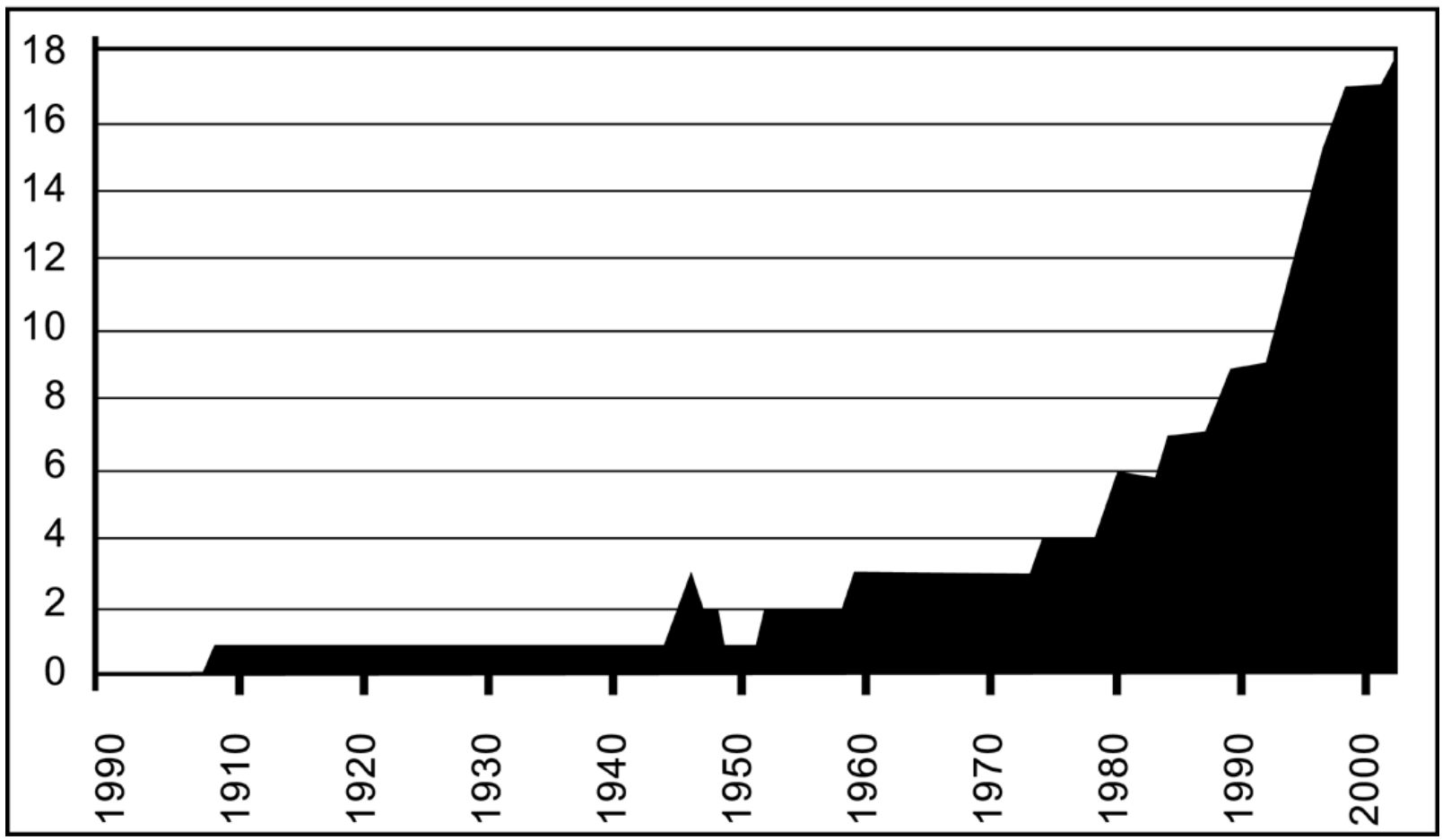




\section{Desarrollo del derecho en la jurisdicción internacional}

Una consecuencia del crecimiento de la jurisdicción internacional ha sido el desarrollo del derecho internacional, en tanto que ha sido aplicado e interpretado por los tribunales. No obstante el lento aumento en la membresía de la Corte Mundial, el incremento en la normatividad internacional en la última década se refleja también en su actividad judicial. La Corte Permanente de Justicia Internacional (CPJI) juzgó 24 casos contenciosos y dictó 25 opiniones consultivas de 1922 hasta su desaparición formal en 1945. Hasta 1996, la Corte Internacional de Justicia (CIJ) había dictado 71 sentencias y 46 opiniones consultivas; y tenía 22 casos pendientes. ${ }^{33}$

Puede pensarse que el incremento indiscriminado de tribunales internacionales podría poner en peligro la unidad del sistema jurídico internacional, ya que al haber varias autoridades interpretando el mismo cuerpo legal, sin que entre ellas opere jerarquía alguna, podrían aparecer inconsistencias. Por ejemplo, en octubre de 2001, el presidente de la Corte Internacional de Justicia, S. E. Gilbert Gilliaume, llamó la atención sobre la proliferación de tribunales internacionales que puede poner en riesgo la unidad del sistema de derecho internacional. ${ }^{34}$ En su discurso frente a la Asamblea General de Naciones Unidas, llamó la atención sobre la posibilidad de que estas cortes puedan solicitar opiniones consultivas a la CIJ, mediante la propia Asamblea General, o el Consejo de Seguridad. En un discurso ante el sexto comité de la Asamblea General, ${ }^{35}$ señaló como ejemplos del riesgo de la falta de unidad en el Caso de la Disputa de los Bancos de Pez Espada entre Chile y Estados Unidos de América; y el Caso del Atún en el Tribunal Internacional sobre Derecho del Mar, entre Japón, Nueva Zelanda y Australia, donde el tribunal arbitral concluyó que prima facie tenía jurisdicción, pero el tribunal arbitral concluyó lo contrario.

Sin embargo, el profesor Jonathan Charney analizó la interpretación del derecho sobre cinco temas fundamentales (fuentes, derecho de los tratados, compensación por daños a extranjeros, responsabilidad internacional, agotamiento de recursos internos, nacionalidad y delimitación maríti-

33 Idem.

34 Speech of His Excellency Gilbert Gilliaume, President of the International Court of Justice to the General Assembly of United Nations, October 30, 2001, www.icj-cij.org.

35 Speech of His Excellency Gilbert Gilliaume, President of the International Court of Justice to the Sixth Committee of the General Assembly of United Nations, October 31, 2001, www.icjcij.org. 
ma). Los tribunales que analizó son la CIJ, la Corte Europea de Justicia, la Corte Europea de Derechos Humanos, la Corte Interamericana de Derechos Humanos, los mecanismos de la OMC, el Tribunal Irán-Estados Unidos de América y tribunales ad hoc. Su conclusión es que no hay disparidades significativas. ${ }^{36}$

Considérese el papel de la CIJ. Es el órgano de jurisdicción general más importante por el número de sus miembros. Aunque éste es el órgano jurisdiccional principal de Naciones Unidas, ${ }^{37}$ y todos los miembros de esta organización son miembros ipso facto también del Estatuto de la corte, ${ }^{38}$ el número de Estados que aceptan la jurisdicción obligatoria de la Corte Mundial ha aumentado a un ritmo constante pero lento. En la página siguiente se muestra una gráfica en donde se aprecia la relación entre los Estados reconocidos en la comunidad internacional y su pertenencia a la Corte Mundial, evidenciando que el ritmo con el que aumenta la penetración de la corte es constante, pero más lento que la progresión de Estados nacientes.

Durante la segunda mitad del siglo XIX, el número de Estados pasó de 44 a 50. Durante el siglo XX el número de Estados llegó casi a 200, incrementándose en cerca de $400 \%$. La gráfica de la página siguiente muestra el incremento de sujetos en el último siglo. ${ }^{39}$ De acuerdo con estos criterios, actualmente existen 190 Estados miembros de Naciones Unidas; el Vaticano mantiene una misión permanente. ${ }^{40}$ Además de Timor Oriental cuya independencia fue declarada este año, no parece que haya otro Estado que esté reconocido y no sea miembro de Naciones Unidas.

La fortaleza de la corte es relativa, según se muestra con algunas cifras sobre su aceptación en la comunidad internacional. Como se aprecia en la gráfica, cada vez más Estados se han sometido a la jurisdicción del órgano judicial de Naciones Unidas. Sin embargo, en 1945 un poco más de la mitad de los miembros aceptaban la jurisdicción de la corte; pero ahora sólo un tercio la acepta. De los 63 países que actualmente aceptan

36 Charney, J., The Impact on the International Legal System of the Growth of International Courts and Tribunals (1999) 31 NYU J Int'1 L \& Pol. 697, 699.

37 CNU 92.

38 CNU, 93 (1); Incluso Suiza, el único Estado reconocido que no es miembro de NU, es parte del Estatuto de la CIJ.

39 El número de Estados se calculó haciendo una aproximación con los datos en Higgins R., The Development of International Law by the Organs of the United Nations, Oxford UP Oxford, 1963, 13; Crawford, J., The Creation of States in International Law, Oxford, Clarendon Press, 1979, 3; y http://www.genevanews.com/gnir/html/Archives/199806/Perspective.html.

40 Http://www.un.org/members/index.html, junio 2001. 
GRÁFICA 2. RELACIÓN ENTRE EL NÚMERO DE ESTADOS RECONOCIDOS

Y SU PERTENENCIA A LA CORTE MUNDIAL 1919-2000

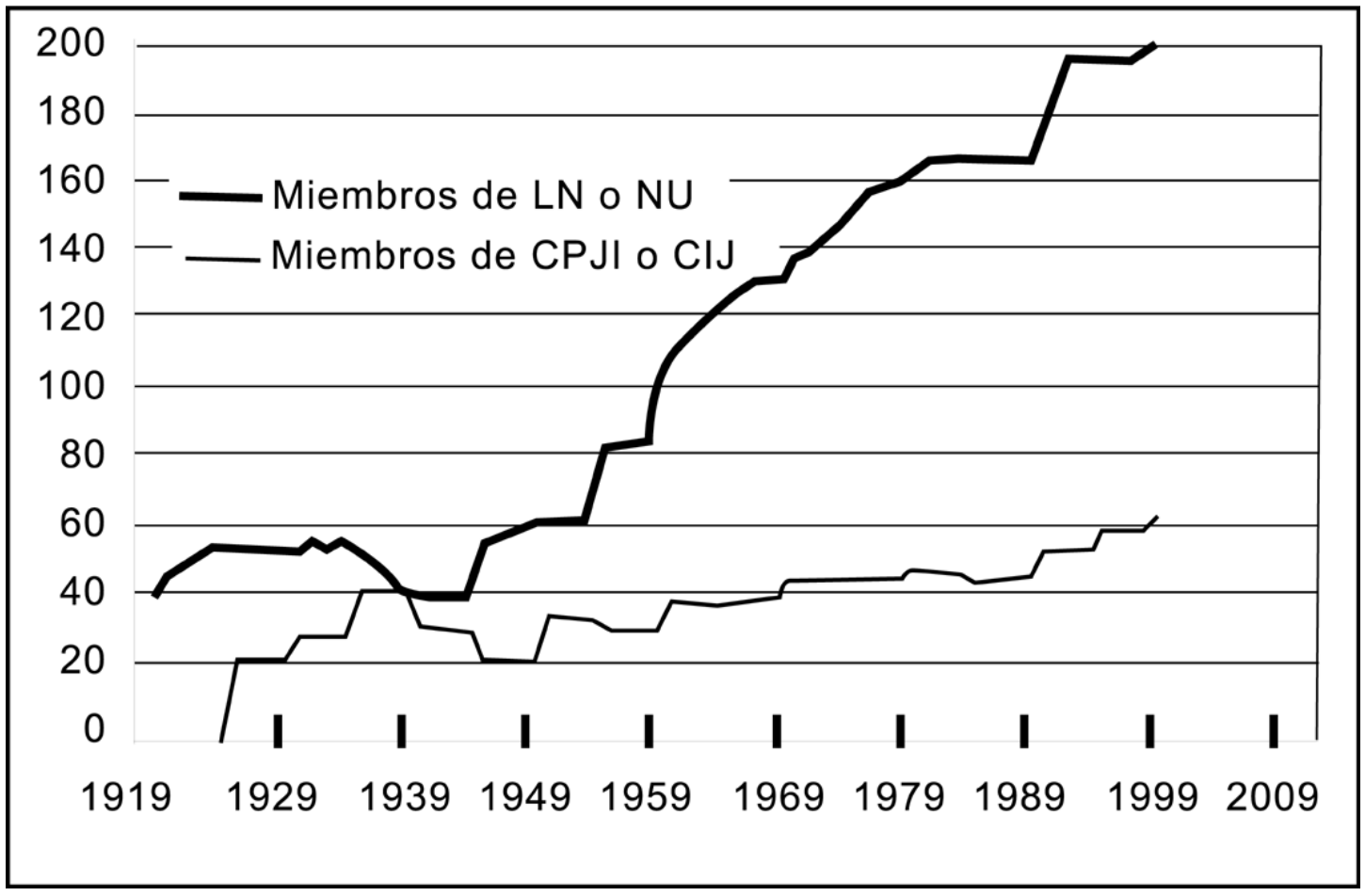


la jurisdicción de la CIJ, sólo seis aceptaron la jurisdicción obligatoria de la CPJI; y 11 de los países que aceptaron la jurisdicción de la CPJI, nunca confirmaron su aceptación de la sucesora. ${ }^{41}$ De los cinco miembros permanentes del Consejo de Seguridad, sólo el Reino Unido acepta la jurisdicción obligatoria de la corte. Rusia y China nunca la han aceptado, y Francia y Estados Unidos de América retiraron su carta de aceptación (EUA, luego de la condena en el caso contra Nicaragua). Existen al menos 400 tratados multilaterales y bilaterales que confieren jurisdicción obligatoria a la CIJ ${ }^{42}$ De modo que aunque los países no acepten su jurisdicción general, pueden aceptarla parcialmente respecto de un instrumento específico. La falta de adhesión a la jurisdicción de la corte puede ser una fuente de debilidad. Al lado del juez Gilliaume, para evitar que surjan contradicciones en el sistema, algunos autores juzgan necesario que la Corte Mundial se fortalezca como centro de este conjunto de instancias judiciales. ${ }^{43}$

\section{Enfoque propuesto}

En este contexto, es prudente tener un enfoque del desarrollo del derecho internacional según su aplicación en las cortes. De este modo, el presente ejercicio describe los fallos de la Corte Internacional de Justicia y de algunos tribunales arbitrales, anotándose algunos antecedentes sobre los temas mencionados en las decisiones. Así, pueden reunirse elementos para valorar si existe una fragmentación del derecho internacional, o no.

Se han analizado las resoluciones judiciales y documentos, de la Corte Internacional de Justicia, el Tribunal Internacional de Derecho del Mar, el Centro Internacional de Arreglo de Controversias de Inversión, los tribunales del Capítulo 11 del TLCAN y la Corte Interamericana de Derechos Humanos.

41 A guide to the history, composition, jurisdiction, procedure and decisions of the Court (19961945), http://www.icj-cij.org/icjwww/igeneralinformation.

42 Idem.

43 Véase, en general, Romano, The Proliferation..., cit., nota 2. 


\begin{tabular}{|c|c|c|c|c|}
\hline CASO & PARTES & FASE & FECHA & TRIBUNAL \\
\hline Caso LaGrand & $\begin{array}{c}\text { Alemania } \\
v s . \text { EUA }\end{array}$ & Fondo & $\begin{array}{l}27 \text { de junio } \\
\text { de } 2001\end{array}$ & CIJ \\
\hline $\begin{array}{l}\text { Caso } \\
\text { concerniente } \\
\text { a la orden } \\
\text { de arresto } \\
\text { del } 11 \text { de abril } \\
\text { de } 2000 \\
\end{array}$ & $\begin{array}{l}\text { Congo- } \\
\text { Bélgica }\end{array}$ & Fondo & & CIJ \\
\hline $\begin{array}{l}\text { Intervención. } \\
\text { Caso } \\
\text { concerniente } \\
\text { a la soberanía } \\
\text { sobre Palau } \\
\text { Ligitan } \\
\text { y Palau } \\
\text { Sipadan } \\
\end{array}$ & $\begin{array}{l}\text { Indonesia- } \\
\text { Malasia }\end{array}$ & $\begin{array}{l}\text { Solicitud } \\
\text { de Filipinas } \\
\text { de permiso } \\
\text { para intervenir }\end{array}$ & $\begin{array}{l}23 \text { de octubre } \\
\text { de } 2001\end{array}$ & CIJ \\
\hline $\begin{array}{l}\text { Discontinuidad. } \\
\text { Caso 'Chaisiri } \\
\text { Reefs 2' }\end{array}$ & $\begin{array}{l}\text { Panamá- } \\
\text { Yemen }\end{array}$ & & $\begin{array}{l}13 \text { de julio } \\
\text { de } 2001\end{array}$ & $\begin{array}{l}\text { ITLOS núm. } \\
9 \text { Orden } \\
2001 / 4\end{array}$ \\
\hline \begin{tabular}{|l} 
Caso de la \\
Planta MOX
\end{tabular} & $\begin{array}{l}\text { Irlanda-Reino } \\
\text { Unido }\end{array}$ & $\begin{array}{l}\text { Medidas } \\
\text { provisionales }\end{array}$ & $\begin{array}{l}25 \text { de octubre } \\
\text { de } 2001\end{array}$ & ITLOS \\
\hline $\begin{array}{l}\text { Víctor Rey } \\
\text { Casado y } \\
\text { Fundación } \\
\text { Allende } \\
\end{array}$ & España-Chile & $\begin{array}{l}\text { Medidas } \\
\text { provisionales }\end{array}$ & $\begin{array}{l}25 \text { de } \\
\text { septiembre } \\
\text { de } 2001\end{array}$ & $\begin{array}{l}\text { Caso CIADI } \\
\text { núm. } \\
\text { ARB/98/2 }\end{array}$ \\
\hline $\begin{array}{l}\text { Autopista } \\
\text { Concesionada } \\
\text { de Venezuela } \\
\end{array}$ & $\begin{array}{l}\text { EUA- } \\
\text { Venezuela }\end{array}$ & Jurisdicción & $\begin{array}{l}27 \text { de } \\
\text { septiembre } \\
\text { de } 2001\end{array}$ & $\begin{array}{l}\text { Caso CIADI } \\
\text { núm. } \\
\text { ARB/00/50 }\end{array}$ \\
\hline \begin{tabular}{|l} 
Minhlay \\
International \\
Corporation \\
\end{tabular} & $\begin{array}{l}\text { EUA-Sri } \\
\text { Lanka }\end{array}$ & Jurisdicción & $\begin{array}{l}15 \text { de marzo } \\
\text { de } 2002\end{array}$ & $\begin{array}{l}\text { Caso CIADI } \\
\text { núm. } \\
\text { ARB/00/2 }\end{array}$ \\
\hline $\begin{array}{l}\text { Armando } \\
\text { Olguín vs. } \\
\text { República del } \\
\text { Paraguay }\end{array}$ & $\begin{array}{l}\text { EUA- } \\
\text { Paraguay }\end{array}$ & Fondo & $\begin{array}{l}26 \text { de julio } \\
\text { de } 2001\end{array}$ & $\begin{array}{l}\text { Caso CIADI } \\
\text { núm. } \\
\text { ARB/98/5 }\end{array}$ \\
\hline
\end{tabular}




\begin{tabular}{|c|c|c|c|c|}
\hline CASO & PARTES & FASE & FECHA & TRIBUNAL \\
\hline $\begin{array}{l}\text { ADF Group } \\
\text { INC vs. Estados } \\
\text { Unidos de } \\
\text { América }\end{array}$ & Canadá-EUA & $\begin{array}{l}\text { Lugar del } \\
\text { arbitraje }\end{array}$ & $\begin{array}{l}11 \text { de julio } \\
\text { de } 2001\end{array}$ & $\begin{array}{l}\text { Caso CIADI } \\
\text { núm. } \\
\text { ARB(AF/00/1) }\end{array}$ \\
\hline $\begin{array}{l}\text { United Parcel } \\
\text { Service } \\
\text { of America }\end{array}$ & EUA-Canadá & $\begin{array}{l}\text { Lugar del } \\
\text { Arbitraje }\end{array}$ & $\begin{array}{l}17 \text { de octubre } \\
\text { de } 2001\end{array}$ & TLCAN \\
\hline $\begin{array}{l}\text { United Parcel } \\
\text { Service of } \\
\text { America }\end{array}$ & EUA-Canadá & $\begin{array}{l}\text { Permiso para } \\
\text { intervenir }\end{array}$ & $\begin{array}{l}17 \text { de octubre } \\
\text { de } 2001\end{array}$ & TLCAN \\
\hline \begin{tabular}{|l} 
Comisión \\
de Libre \\
Comercio \\
del TLCAN \\
\end{tabular} & $\begin{array}{l}\text { EUA-Canadá- } \\
\text { México }\end{array}$ & $\begin{array}{l}\text { Nota } \\
\text { interpretativa }\end{array}$ & $\begin{array}{l}31 \text { de julio } \\
\text { de } 2001\end{array}$ & TLCAN \\
\hline Methanex Corp. & Canadá-EUA & $\begin{array}{l}\text { Segunda } \\
\text { opinión } \\
\text { del profesor } \\
\text { Jennings }\end{array}$ & $\begin{array}{l}6 \text { de } \\
\text { septiembre } \\
\text { de } 2001\end{array}$ & TLCAN \\
\hline Metalcald Corp & $\begin{array}{l}\text { México- } \\
\text { Canadá }\end{array}$ & \begin{tabular}{|l} 
Razones \\
suplementarias \\
del juicio \\
\end{tabular} & $\begin{array}{l}\text { Octubre de } \\
2001\end{array}$ & \begin{tabular}{|l} 
BCSC \\
Vancouver \\
Canadá \\
\end{tabular} \\
\hline $\begin{array}{l}\text { Pope \& Talbot } \\
\text { Inc. }\end{array}$ & EUA-Canadá & Daños & $\begin{array}{l}31 \text { de abril } \\
\text { de } 2002\end{array}$ & $\begin{array}{l}\text { CIADI Caso } \\
\text { núm. } \\
\text { ARB(AF) }\end{array}$ \\
\hline $\begin{array}{l}\text { Caso Las } \\
\text { Palmeras }\end{array}$ & Colombia & Fondo & $\begin{array}{l}6 \text { de } \\
\text { diciembre } \\
\text { de } 2001\end{array}$ & $\begin{array}{l}\text { Corte IDH } \\
\text { serie C } \\
\text { núm. } 90 \\
\end{array}$ \\
\hline $\begin{array}{l}\text { Caso Baruch } \\
\text { Ivcher Bronstein }\end{array}$ & Perú & $\begin{array}{l}\text { Interpretación } \\
\text { de la } \\
\text { sentencia } \\
\text { de fondo } \\
\end{array}$ & $\begin{array}{l}4 \text { de } \\
\text { septiembre } \\
\text { de } 2001\end{array}$ & $\begin{array}{l}\text { Corte IDH } \\
\text { serie C } \\
\text { núm. } 84\end{array}$ \\
\hline $\begin{array}{l}\text { Caso Barrios } \\
\text { Altos. } \\
\text { Chumbi Puma } \\
\text { Aguirre y otros } \\
\end{array}$ & Perú & $\begin{array}{l}\text { Interpretación } \\
\text { de la } \\
\text { Sentencia } \\
\text { de fondo } \\
\end{array}$ & $\begin{array}{l}3 \text { de } \\
\text { septiembre } \\
\text { de } 2001\end{array}$ & $\begin{array}{l}\text { Corte IDH } \\
\text { serie C } \\
\text { núm. } 83\end{array}$ \\
\hline
\end{tabular}




\begin{tabular}{|c|c|c|c|c|}
\hline CASO & PARTES & FASE & FECHA & TRIBUNAL \\
\hline \begin{tabular}{|l} 
Caso Barrios \\
Altos. \\
Chumbi Puma \\
Aguirre y otros \\
\end{tabular} & Perú & Reparaciones & $\begin{array}{l}30 \text { de } \\
\text { noviembre } \\
\text { de } 2001\end{array}$ & $\begin{array}{l}\text { Corte IDH } \\
\text { serie C } \\
\text { núm. } 87\end{array}$ \\
\hline \begin{tabular}{|l} 
Caso \\
Gustavo \\
Cesti Hurtado \\
\end{tabular} & Perú & $\begin{array}{l}\text { Interpretación } \\
\text { de la sentencia } \\
\text { de fondo }\end{array}$ & $\begin{array}{l}27 \text { de } \\
\text { noviembre } \\
\text { de } 2001\end{array}$ & $\begin{array}{l}\text { Corte IDH } \\
\text { serie C } \\
\text { núm. } 86 \\
\end{array}$ \\
\hline \begin{tabular}{|l} 
Caso \\
Cantoral \\
Benavides \\
\end{tabular} & Perú & Reparaciones & \begin{tabular}{|l}
3 de \\
diciembre \\
de 2001 \\
\end{tabular} & $\begin{array}{l}\text { Corte IDH } \\
\text { serie C } \\
\text { núm. } 88\end{array}$ \\
\hline Caso Hilaire & $\begin{array}{l}\text { Trinidad } \\
\text { y Tobago }\end{array}$ & $\begin{array}{l}\text { Excepciones } \\
\text { preliminares }\end{array}$ & \begin{tabular}{|l}
1 de \\
septiembre \\
de 2001 \\
\end{tabular} & $\begin{array}{l}\text { Corte IDH } \\
\text { serie C } \\
\text { núm. } 80 \\
\end{array}$ \\
\hline $\begin{array}{l}\text { Caso Benjamín } \\
\text { y otros }\end{array}$ & $\begin{array}{l}\text { Trinidad } \\
\text { y Tobago }\end{array}$ & $\begin{array}{l}\text { Excepciones } \\
\text { preliminares }\end{array}$ & \begin{tabular}{|l}
1 de \\
septiembre \\
de 2001
\end{tabular} & $\begin{array}{l}\text { Corte IDH } \\
\text { serie C } \\
\text { núm. } 81 \\
\end{array}$ \\
\hline \begin{tabular}{|l} 
Caso \\
Constantine vs. \\
Otros
\end{tabular} & $\begin{array}{l}\text { Trinidad } \\
\text { y Tobago }\end{array}$ & $\begin{array}{l}\text { Excepciones } \\
\text { preliminares }\end{array}$ & $\begin{array}{l}1 \text { de } \\
\text { septiembre } \\
\text { de } 2001\end{array}$ & $\begin{array}{l}\text { Corte IDH } \\
\text { serie C } \\
\text { núm. } 82 \\
\end{array}$ \\
\hline Caso Cantos & Argentina & $\begin{array}{l}\text { Excepciones } \\
\text { preliminares }\end{array}$ & $\begin{array}{l}2 \text { de } \\
\text { septiembre } \\
\text { de } 2001\end{array}$ & $\begin{array}{l}\text { Corte IDH } \\
\text { serie C } \\
\text { núm. } 85 \\
\end{array}$ \\
\hline \begin{tabular}{|l} 
Caso de la \\
Comunidad \\
Mayagna \\
(Sumo) \\
Awas Tingni \\
\end{tabular} & Nicaragua & Fondo & $\begin{array}{l}31 \text { de agosto } \\
\text { de } 2001\end{array}$ & $\begin{array}{l}\text { Corte IDH } \\
\text { serie C } \\
\text { núm. } 70\end{array}$ \\
\hline
\end{tabular}

De acuerdo con su tema principal, se han distribuido las sentencias en cuatro secciones: (i) Aspectos procesales; (ii) Reglas de atribución; (iii) Temas sustantivos; y (iv) Reparaciones. En la primera sección se incluyen temas de jurisdicción, medidas provisionales, permiso para intervenir y lugar de arbitraje. En la segunda se incluyen casos que tratan sobre la nacionalidad de las personas físicas o morales afectadas por un acto de Estado, y determinan la admisibilidad de la queja. Los temas sustantivos incluyen asuntos de relaciones consulares; inmunidad del ministro de asuntos exteriores; derechos relativos a la protección de la inversión; es- 
tándar de trato a extranjeros bajo el TLCAN, y derechos de propiedad de las comunidades indígenas. Finalmente, en la sección de reparaciones sobresale la jurisprudencia de la Corte Interamericana de Derechos Humanos.

\section{ASPECTOS PROCESALES}

\section{Métodos de trabajo de la Corte Internacional de Justicia}

En junio de 2002 había 23 casos pendientes en la corte, más que nunca antes. Desde 1998 la corte adoptó medidas para recomendar acciones a las partes que contribuyeran al desahogo más veloz de los procedimientos. El primer documento sobre el tema fue la nota relativa a recomendaciones a las partes que registren nuevos casos (1998, comunicado de prensa 98/14), encaminada a reducir el número de anexos documentales en las demandas, y el número de rondas de argumentos escritos intercambiados. Continuando con este proceso, en 2001 se adoptaron las directivas de prácticas, ${ }^{44}$ recomendando a las partes la aplicación estricta del artículo 43 de las reglas de la corte.

Así, para la eficiencia de la fase escrita, se favorecerá una sola ronda de intercambios de argumentos escritos; la segunda será autorizada sólo si las circunstancias del caso lo ameritan a juicio de la corte. Se puso énfasis también sobre el intercambio de documentos una vez cerrada la fase escrita, de modo que se puedan introducir nuevos documentos sólo con el consentimiento de la contraparte; o con la autorización especial de la corte. Y la respuesta debe limitarse al nuevo documento introducido. Se espera además que las partes acuerden el número y orden de sus pretensiones en el acuerdo especial que le concede jurisdicción. Se estableció además un límite de cuatro meses para presentar objeciones preliminares.

Además, se puso énfasis en la aplicación del artículo 60.1 de las reglas de la corte, para lograr que los procedimientos orales no duren más de lo necesario. En el mismo sentido, la corte pretende hacer más uso de las reglas que le permiten deliberar para identificar cuáles son los puntos que las partes deben tratar en las audiencias. Se reserva además el derecho de excluir los procedimientos preliminares de la regla de intercambio de notas de los jueces, prevista en la Resolución de Práctica Judicial Interna de 1978 (Press Release 98/14). 
Resalta el hecho de que se solicitó no se designara a jueces ad hoc que hayan actuado como abogados ante la corte durante tres años, ni se empleen abogados que hayan actuado como oficiales de la corte en el mismo periodo.

\section{Jurisdicción}

- Caso Hilaire vs. Trinidad y Tobago. Corte IDH serie C núm. 80 (excepciones preliminares) septiembre 1 de 2001.

- Caso Benjamín y otros vs. Trinidad y Tobago. Corte IDH serie C núm. 81 (excepciones preliminares) sentencia de septiembre 1 de 2001.

- Caso Constantine vs. Otros vs. Trinidad y Tobago. Corte IDH serie C núm. 82 (excepciones preliminares) sentencia de septiembre 1 de 2001

\section{Medidas provisionales}

\section{A. Caso de la Planta MOX (Irlanda vs. Reino Unido)} ITLOS octubre 25, 2001

El objeto de la disputa es la construcción de una planta para convertir combustible nuclear en combustible de óxidos mixtos (Mixed oxide fuel). Irlanda contiende que la construcción de la planta implica un riesgo para las aguas irlandesas por el transporte de material radioactivo. Por eso, Irlanda solicitó la institución de un tribunal arbitral bajo el anexo VII de la Convención de Naciones Unidas de Derecho del Mar, y la aplicación de medidas provisionales por el ITLOS, mientras se instala el tribunal arbitral.

El Reino Unido objetó que el ITLOS no era competente para solicitar medidas provisionales, porque éstas involucraban la aplicación de tratados regionales entre las partes. Sin embargo, el tribunal decidió que estas medidas requieren sólo de la aplicación de la Covemar.

Además, el Reino Unido argumentó que al no haber intercambio de opiniones entre las partes sobre la disputa, el requisito del artículo 293 no se cumple. El tribunal, por su parte, decidió que no existe ninguna obligación de mantener conversaciones para solucionar la controversia cuando no es probable que se solucione por ese medio, por lo tanto, el tribunal arbitral, en el anexo VII, tiene competencia en el caso. Esta decisión parece basada sobre la consideración del peso de las negociaciones previas para acceder a medios jurisdiccionales de solución controversias. En esta resolución, el ITLOS parece seguir el principio de que tales negociaciones son un requisito en tanto que puedan ser efectivas, como fue el Caso 
de las concesiones palestinas de Mavromatis, ${ }^{45}$ y la aplicabilidad de la obligación de someterse a arbitraje. ${ }^{46}$

Más adelante, el tribunal tomó nota de que el transporte del material radioactivo no comenzaría sino hasta el verano de 2002, y considerando la pronta instalación del tribunal arbitral, no consideró necesario ordenar las medidas requeridas por Irlanda. Sin embargo, con el fin de preservar la cooperación internacional en la prevención del daño ambiental, ordenó a las partes el intercambio de información sobre los riesgos y efectos de la planta MOX.

\section{B. Víctor Rey Casado y Fundación Allende vs. Chile (Medidas provisionales) Caso CIADI núm. ARB/98/2, septiembre 25, 2001}

El caso versa sobre la confiscación de compañías editoras supuestamente propiedad del demandante, entre los años 1972 y 1975, bajo el tratado bilateral de inversión entre Chile y España de 1991. En este caso el actor demanda se ordene la suspensión de la ejecución de la orden 43 del gobierno chileno que determinará el valor de la indemnización de cierta propiedad, supuestamente en manos del actor. El tribunal examinó la relevancia de la medida gubernamental, su identidad con la materia del caso arbitral. El actor alega que la orden se ejecutará sobre la propiedad materia del caso frente al CIADI. Además, en 1999 el Estado solicitó medidas provisionales para que el actor garantice las costas judiciales. El panel, presidido por el profesor Bedjoui, se involucró en una exhaustiva discusión de la naturaleza de las medidas provisionales y la facultad del tribunal para determinarlas en un caso en donde una parte contiende la jurisdicción del tribunal.

Primero, el tribunal indagó sobre la naturaleza de las medidas provisionales y decidió que, dada la naturaleza de esta institución, sí tiene jurisdicción para dictarlas. Se basó el tribunal en el único requisito aplicado por la Corte Internacional de Justicia, i. e. la jurisdicción prima facie. El tribunal afirmó que el examen de jurisdicción prima facie es similar al registrar el secretario del CIADI una disputa, siempre que no esté clara-

45 Mavrommatis Palestine Concessions Case (Greece vs. UK) 1924 PCIJ series A, núm. 2, p. 13.

46 Applicability of the Obligation to Arbitrate under Section 21 of the United Nations Head-quarters Agreement of 26 June 1947 (Advisory Opinion) 26 April 1988, ICJ Reports 1988, p. 12 , parágrafo 33,4 . 
mente fuera de la jurisdicción del tribunal. (8)* La aplicación de este examen es consistente con la decisión de la CIJ en Pesquerías (Islandia vs. Reino Unido) y en el Caso de Holiday Inn vs. Marruecos del CIADI. Además, concluye el tribunal que estas medidas no tiene fuerza de res judicata y pueden ser revocadas en cualquier tiempo. (14) Puede además el tribunal rechazar las medidas requeridas por las partes y ordenar otras distintas. (16) Además, haciendo referencia al Caso La Grand de la CIJ, el tribunal señala el carácter vinculatorio de tales medidas, refiriéndose también a que el artículo 41 del Estatuto de la corte fue la base del artículo análogo en la Convención del CIADI. (21) Igualmente, mencionó que al igual que en Mafferzini vs. España del CIADI, "recomendar" en las reglas del centro equivale a ordenar. El tribunal basó su decisión en otras decisiones, como Rockwell vs. Irán, del Iran US Claims Tribunal, y se refirió al profesor Hudson quien señala la obligatoriedad de tales medidas. (23-4) Finalmente, se refirió al principio general de que las partes no deben tomar ninguna medida que empeore la controversia. (25)

La solicitud de medidas provisionales busca suspender la ejecución de una orden de abril de 2000 que ejecuta presunta propiedad del actor, alegando las consecuencias irrevocables de tal ejecución. (28) El gobierno argumenta que la medida alegada es sobre un derecho hipotético, aún no establecido, y que suspenderla requeriría prejuzgar sobre el fondo del caso. La decisión 43 emite una indemnización al diario Saint Marie, referido a la titularidad de las acciones de CPP, cuyos bienes fueron confiscados en 1971. El actor alega que este es exactamente el mismo litigio frente al tribunal. El tribunal, no obstante, encuentra que la decisión 43 no fija definitivamente el asunto de la indemnización, y aunque con esta medida Chile de por cerrado el caso en derecho interno, esto no prejuzga sobre la decisión del tribunal. (40) El tribunal hace notar que la disputa de la decisión 43 no es en sustancia la misma del caso en cuestión, porque aquélla involucra claramente a otros sujetos además de las partes del Caso CIADI. Sin embargo, sí guarda semejanzas con el caso actual porque el actor se declara dueño de las 40 mil acciones de CPP; sobre cuyos bienes versa la indemnización de la decisión 43. (40) En todo caso, el compartir ciertos elementos no hacen que los casos sean iguales. (59) Además, aunque la decisión en derecho interno fuera definitiva, no tiene impacto

Los números entre paréntesis que se encuentran a lo largo del texto, remiten al número de párrafo de la resolución a que se está haciendo alusión. 
sobre la propiedad de las acciones de la compañía CPP, aunque presuponga una toma de posición respecto de tal propiedad. En cualquier caso, es la función del tribunal evaluar el asunto de la propiedad, independientemente de la decisión 43.

Respecto de la medida solicitada por el Estado para garantizar el pago de costas judiciales, el tribunal no encuentra que esté autorizado para ordenar esto bajo los textos legales del CIADI. (86) Tampoco en la jurisprudencia arbitral relevante encuentra el tribunal una conclusión diferente. (87) Finalmente, el tribunal no encontró un riesgo de falta de pago de costas por parte del actor. (89)

\section{Intervención}

\section{A. Caso concerniente a la soberanía sobre Palau Ligitan}

y Palau Sipadan (Indonesia vs. Malasia). Solicitud de Filipinas de permiso para intervenir. CIJ octubre 23, 2001

Esta decisión versa sobre la solicitud de Filipinas para intervenir en el procedimiento entre Indonesia y Malasia, a su vez instituido por el Acuerdo Especial de mayo 31 de 1997 para resolver la cuestión de la soberanía sobre Palau Ligitan y Palau Sipadan. La solicitud fue presentada en noviembre de 1998 y desde entonces se notificó a los miembros de Naciones Unidas y de otros países que pudieran tener derecho de aparecer frente a la corte. El 13 de marzo de 2001 Filipinas solicitó permiso para intervenir en el caso principal, bajo el amparo del artículo 62 del Estatuto de la corte. El objeto de la intervención se basa en los derechos que Filipinas alega tener sobre Borneo del Norte, es decir, un territorio que no es disputado por las partes del caso principal. El interés de Filipinas es que al interpretar algún documento empleado por las partes, la corte podría adoptar una interpretación adversa a sus intereses sobre Borneo del Norte, negando la soberanía del Sultán de Sulu sobre este territorio. Ambas partes del caso expresaron estar en contra de la intervención de las Filipinas.

Los requisitos del artículo 81 de las reglas de la corte indican que no se debe solicitar permiso antes del cierre del procedimiento escrito; debe acreditarse un interés legal, el objeto de la intervención, un nexo jurisdiccional, y una lista de los documentos ofrecidos como pruebas. (16) La corte examinó cada uno de ellos.

Respecto del momento de presentar la solicitud de intervención, la corte hizo notar que Filipinas estaba al tanto de los procedimientos desde 
noviembre de 1998, cuando fue instaurado por las partes, y conocía el calendario de la fase escrita. Conocía que las partes estaban facultadas para someter nuevas demandas a la corte en una segunda ronda de escritos, pero no era una obligación. A pesar de esto, Filipinas no solicitó permiso para intervenir, sino 10 días antes de la conclusión del periodo permitido, objetando que como carecía de las demandas de las partes, no podía preparar sus argumentos. A pesar de esto, la corte no podría decir que Filipinas faltó al requisito de las reglas, ya que restaban 10 días para que el plazo para someter la solicitud expirara. Además, no fue sino hasta marzo 28 que se supo que la última ronda de argumentos escritos no se abriría por no desearlo las partes. (20-4)

Más adelante, la corte comentó sobre la objeción de Indonesia, de la ausencia de evidencia presentada por Filipinas. Sin embargo, esto, lejos de ser una obligación del gobierno, es una facultad, y los medios que emplee el solicitante para probar su posición son de libre elección. (27.30)

Respecto de la necesidad de un nexo jurisdiccional independiente, la corte aclaró que el procedimiento incidental en cuestión no tiene la finalidad de transformar el caso, y la jurisdicción de la corte se basa en la reclamación original. De requerirse una base de jurisdicción independiente en este caso, se transformaría el caso, y Filipinas sería admitido como una nueva parte. (31-7)

En la opinión de la corte, Filipinas no estableció un interés legal adecuado ni lo probó de modo suficiente. La corte decidió que el concepto de interés legal(47-56) es más amplio que el alcance del dispositif de la decisión final. El obstáculo para la intervención sería que la corte tuviera que prejuzgar por la intervención, el fondo de otra disputa que debiera serle sometida. Así razonó la corte cuando a Malta se le denegó permiso para intervenir en el Caso de la Plataforma Continental entre Túnez y Libia, porque la intervención implicaba prejuzgar la disputa entre Malta y Túnez. (53) Además, Filipinas argumentó que el interés legal es subjetivo, que el Estado debe identificar y relacionar al caso principal. Sin embargo, la corte aclaró que este interés debe ser establecido de modo convincente, vgr., qué razonamiento de la corte podría afectar los derechos de Filipinas sobre Borneo del Norte, y de qué modo. (57-63)

En tanto que Filipinas argumenta la posible interpretación que la corte hiciera de algún documento que las parte emplearían como evidencia, se analizó con cuidado cada una de las bases documentales sobre las que descansa su reclamo. 
La Convención de 1930 entre Estados Unidos de América y el Reino Unido fija los límites entre Filipinas y Borneo del Norte. Por su parte, Malasia arguye que este documento transforma los derechos de administración de la British North Borneo Company en derechos de soberanía. Filipinas arguye que de la soberanía del Sultán de Sulu sobre Borneo del Norte se sigue que la cesión de derechos de las islas al sur y al oeste de la línea divisoria, fue de parte del Sultán. La corte opina que esta Convención asigna derechos al Archipiélago de Filipinas (Estados Unidos de América) y para Borneo del Norte (protegido por Reino Unido), pero no discute el estatus del territorio principal de Borneo. Especialmente, Filipinas no mostró cómo alguna interpretación de esta convención podría afectar su reclamo territorial sobre Borneo del Norte.

Por otro lado, Indonesia empleó el intercambio de notas entre el Reino Unido y Estados Unidos de América de 1907, para aseverar que existe algún vínculo entre el territorio disputado y Borneo del Norte. Y aunque Filipinas contiende que este documento evidencia que el Reino Unido no era soberano de Borneo del Norte, el tipo de vínculo existente no es importante para la corte, ni tiene que decidir si es un vínculo de soberanía del Reino Unido, o no. (71-4)

El último documento empleado tanto por Filipinas como por las partes del caso, es la Orden de Cesión de 1946, en donde el Reino Unido reconoce la cesión de la soberanía sobre Borneo del Norte. Filipinas reclama que el documento no es válido, e Indonesia reclama el impacto que el documento tiene sobre el territorio disputado en el caso principal. Por esto la corte concluye que el interés de Filipinas sobre él, es demasiado remoto.

El resto de los documentos en los que Filipinas basa su argumento, no son empleados por las partes. La base principal de Filipinas para reclamar derechos sobre Borneo del Norte, es la Concesión del Sultán de Sulu de 1878. (64) El argumento de Filipinas es que en 1878 este documento prueba que el Sultán no cedió al Reino Unido los derechos territoriales de Borneo del Norte. Pero ninguna de las partes reclama soberanía sobre el terreno disputado con base en este documento; el ámbito de ese documento no incluye el terreno disputado, y si constituyó o no una renta y no una cesión no se discute en este caso. Filipinas invocó además el Protocolo entre Gran Bretaña, Alemania, y España de 1885. Pero nuevamente, las partes no se basan en él para argumentar su caso. El mismo caso se presentó con la Carta Real de 1881, en donde Filipinas basa la prueba de la 
definitiva cesión de derechos hasta 1903. Pero tampoco se usa este documento en los argumentos de las partes, ni se discute cuál era el estatus de Borneo del Norte en ese momento. Enseguida, Filipinas argumentó que la Convención de 1891 entre Reino Unido y Países Bajos define a Borneo del Norte como un Estado protegido del Reino Unido. Sin embargo, el área en disputa esta debajo del alcance de esta convención.

En suma, aunque Filipinas mostró tener algún interés legal en la disputa, no mostró un interés específico, es decir, una interpretación de un documento que la corte pudiera adoptar, y pudiera afectar la aserción de que el Sultán de Sulu conserva la soberanía sobre Borneo del Norte. Los documentos ofrecidos no son la base principal del reclamo de Filipinas, ni la base de la disputa principal frente a la corte, y el argumento de Filipinas es en suma, demasiado remoto. (83)

Cabe anotar que las opiniones separadas y disidentes integradas a la decisión, versan sobre el derecho de intervenir en general; mientras que la opinión del profesor Franck versa sobre el impacto del derecho a la autodeterminación en este caso.

\section{B. United Parcel Service of America vs. Canadá (decisión sobre permiso para intervenir) octubre 17, 2001}

\section{Discontinuidad. Caso 'Chaisiri Reefs 2' (Panamá vs. Yemen)} ITLOS núm. 9 Orden 2001/4 julio 13, 2001

Panamá solicitó, bajo el artículo 292 de la Convención de Naciones Unidas de Derecho del Mar, la liberación de barcos, su carga y tripulación, que fueron apresados por Yemen. En esta orden se descontinúan los procedimientos por la liberación de la propiedad y personas detenidas. Se ordenó además la remoción del caso de la lista, de acuerdo con el artículo 105.2 de las reglas del tribunal.

\section{Lugar del arbitraje}

A. ADF Group INC vs. Estados Unidos de América, Caso $C I A D I$ núm. ARB $(A F(/ 00 / 1)$ (orden procesal núm. 2 , relativa al lugar del arbitraje), julio 11, 2001

La disputa versa sobre la determinación del lugar del arbitraje, que puede ser Canadá o Estados Unidos de América. En la resolución puede 
verse con claridad el proceso de interpretación de tratados que confieren competencia al tribunal.

Primero, el tribunal debe decidir con base en las reglas que gobiernan los procedimientos, $i$. e. las reglas del CIADI. Pero estas sólo lo permiten decidir luego de consultar con las partes, y lo faculta para reunirse en cualquier lugar, vgr., con el fin de inspeccionar bienes o documentos. Las reglas de arbitraje de Uncitral sólo indican que debe decidirse según las circunstancias del caso. Ante la falta de claridad en estas reglas, vinculantes sobre el tribunal por virtud del acuerdo de las partes, el tribunal se refiere a un documento no vinculante, pero que puede arrojar luz en la decisión: las notas de Uncitral sobre procedimientos arbitrales. Los puntos a considerar son cinco: 1. Lo adecuado de las reglas de procedimiento arbitral en el lugar; 2. Un tratado bilateral o multilateral para la ejecución de sentencias arbitrales; 3. La conveniencia de los árbitros y las partes; 4. La disponibilidad de servicios de apoyo; y 5. El lugar en donde se encuentra el objeto de la disputa.

Sobre lo adecuado de las reglas de procedimiento arbitral, las reglas de Canadá fueron criticadas por la falta de certeza del alcance de la revisión judicial. En ambos lugares se ejecutan los laudos calificados de "comerciales", según el derecho interno, y al mismo tiempo, el artículo 1135 del TLCAN dispone que "comercial" es lo comprendido en la sección B. Esto implica que en general ambos lugares son adecuados para el arbitraje. Pero el actor argumenta que en Québec la revisión de laudos es más clara porque no se distingue entre disputas "comerciales" y "no comerciales" de acuerdo con la Ley Modelo de Uncitral. Por el contrario, en Estados Unidos de América, el Acta Federal de Arbitraje no especifica con suficiente claridad en qué casos se revisarán y descartarán los laudos arbitrales, lo que convierte a Estados Unidos de América en un lugar menos adecuado para llevar a cabo el arbitraje. (12-13)

El demandado ofreció como defensa la resolución de Metalclad Corporation, en donde la Corte Suprema de British Columbia se refirió a una decisión americana de Mitsubishi Motors ${ }^{47}$ a favor del respeto por las decisiones de los tribunales arbitrales. La Corte de British Columbia dijo entonces que las razones de Mitsubishi son tan fuertes en la jurisdicción de EUA como en cualquier otra. Además, las condiciones para anular un 
laudo arbitral están claramente establecidas en el capítulo 1 del Acta Federal de Arbitraje de Estados Unidos de América. (14-15)

Por las razones del demandado, el tribunal no está convencido de que deba separarse de las decisiones de otros casos como Methanex o Ethyl, en donde se dijo que ambas reglas (Canadá y Estados Unidos de América) son igualmente convenientes para el arbitraje.

El resto de los criterios de las Notas de UNCTAD parece favorecer al demandado. El tribunal encontró que ambas partes son miembros de la Convención de Nueva York para la ejecución de laudos arbitrales, de modo que este criterio debe eliminarse. Sin embargo, la conveniencia de las partes parece pesar ligeramente en favor de EUA, el cual argumentó que dicha parte está integrada por varias agencias diferentes en el territorio de EUA. Además, el CIADI opina que los costos del procedimiento se reducirían en Washington D. C. Más aún, el objeto de la disputa se refiere a medidas aplicadas por autoridades de EUA, localizadas en este territorio; en contra de un proyecto localizado cerca de D. C. (17-22)

Aunque puede parecer que la neutralidad del tribunal se vería afectada por estar en la capital de una de las partes, esto no es inconveniente porque el arbitraje se celebraría en el CIADI, que es neutral. El tribunal se reserva el derecho de reunirse en Montreal si fuera necesario.

\section{B. United Parcel Service of America vs. Canadá (decisión sobre el lugar del arbitraje) octubre 17, 2001}

Nuevamente fue necesario que un panel decidiera entre Canadá y Estados Unidos de América lugar para celebrar el arbitraje. Se aplicaron también los criterios de las notas de UNCTAD referidas en el caso anterior.

El actor arguyó que la posición de Canadá en el Caso Metalclad sugiere una actitud a favor de un estándar más alto de revisión judicial para los paneles arbitrales, que la existente en Estados Unidos de América. Esto implica que el segundo sea un lugar más adecuado para celebrarlo.

Sin embargo, nuevamente se ofreció al tribunal el empleo de la corte suprema de British Columbia de la decisión estadounidense en el Caso Mitsubishi, para mostrar que el estándar de revisión judicial en ambos países es el mismo. (9) Además, se hizo referencia a los paneles anteriores que designaron a Estados Unidos de América y Canadá como lugares adecuados para celebrar el arbitraje. Sin embargo, el tribunal hizo notar 
que sea cual fuere el lugar del arbitraje, cuán adecuado fuese el mecanismo de adopción de laudos arbitrales en cada país, será relevante de nuevo cuando la sentencia deba ser ejecutada, independientemente del lugar en que la disputa se haya resuelto. (10)

Destaca este caso porque el tribunal expresó su preocupación sobre la actitud de Canadá en el Caso Metalclad. (11) Esto, además de la neutralidad que pesa a favor de la celebración del arbitraje en el CIADI, Washington, D. C., llevaron al tribunal a decidir a favor de celebrar el arbitraje en Estados Unidos de América. (18-19)

\section{REGLAS DE ATRIBUCIÓN}

1. Casos Cantos vs. Argentina Corte IDH serie C núm. 85 (excepciones preliminares) sentencia de septiembre 2, 2001 y Autopista Concesionada de Venezuela vs. República Bolivariana de Venezuela (jurisdicción) Caso CIADI núm. ARB/00/50, septiembre 27, 2001

La decisión concierne a la aplicación de la Convención del CIADI en el caso de una empresa venezolana, originalmente subsidiaria de Emica, empresa mexicana; transferida a una empresa estadounidense ICA Tech, a su vez subsidiaria de la misma empresa mexicana.

En 1995 se subastó el sistema carretero Caracas-La Guaira y se adjudicó a la compañía mexicana ICA. Ésta es una subsidiaria de Empresas ICA, Sociedad Controladora, S. A de C. V. (Emica). La subsidiaria constituyó a su vez la empresa Aucoven, siendo dueña del 99\% de sus acciones. (9) En 1996, Aucoven y el gobierno de Venezuela firmaron el acuerdo base de la demanda para la construcción del proyecto. (12) Como resultado del acuerdo, Aucoven podría cobrar las cuotas de peaje durante 30 años, y el país se obligó a proporcional un equilibrio económico y financiero, $i$. e. que la compañía recuperaría sus costos y tendría ganancias. (13) De no ser así, el país se comprometió a otorgar una compensación en casos no atribuibles a Aucoven.

Por otra parte, ICA Tech es una compañía estadounidense incorporada en Florida, subsidiaria de Emica, propietaria de sus acciones totalmente. (15-7) ICA Tech compró proyectos extranjeros, aparentemente por que ello facilitaba su manejo, luego de la crisis de 1995 en México. (17) 
En 1997, una semana después de que el acuerdo entre Aucoven y el gobierno entró en vigor, Aucoven solicitó al ministro de infraestructura que autorizara la transferencia del $75 \%$ de sus acciones a ICA Tech. (18) En agosto de 1887, la oficina de concesiones remitió la solicitud al departamento legal diciendo que la transferencia le parecía legal. (20) Más adelante, el ministro exigió una garantía a la compañía controladora Emica, que aceptó en abril de 1998. (22) Se le preguntó al abogado general si era necesario que el presidente autorizara la transferencia, a lo que el abogado contestó que no, porque el ministro era responsable de la operación, según lo evidenciaba una carta del ministro al abogado general. (24) El 30 de junio de 1998, ICA Tech se volvió dueña del 75\% de Aucoven. (26)

En agosto de 1998, Aucoven solicitó que el restante $25 \%$ se transfiriera a ICA Tech. Nunca se autorizó la operación. Los accionistas de Aucoven decidieron que la empresa quedaba sujeta al control extranjero de ICA Tech, y transfirieron la decisión al ministro. (28) El ministro señaló en una decisión administrativa que su oficina no podría reconocer ningún acto que cambiara el domicilio o nacionalidad de la compañía a menos que el congreso lo autorizara previamente. (29) Dijo además que el contrato de concesión, según la Constitución, no estaba sujeto a demandas extranjeras. (29) En una decisión de apelación, una corte venezolana decidió que las cláusulas arbitrales del contrato entre el gobierno y Aucoven, estaban en vigor. (30) Surgieron desacuerdos entre las partes, especialmente sobre el aumento de las cuotas. En marzo de 2000 se solicitó un arbitraje. (35) Aucoven comunicó al ministro su decisión de terminar el acuerdo, comprometiéndose a realizar las labores de mantenimiento y recolección de cuotas. Le solicitó además al ministro que terminara el procedimiento administrativo iniciado en septiembre de 1999, y declarara que la disputa debía someterse al panel arbitral. (34)

Aucoven pretende que está controlada por ICA Tech y que el gobierno aceptó el acuerdo del CIADI con base en el control extranjero de la empresa. (38) Sin embargo, Venezuela mantuvo que la empresa está controlada por Emica y se basa en la actuación de autoridades mexicanas de la empresa, etcétera. Argumentó además que el control de Emica era la condición para que se autorizara la transferencia de acciones de Aucoven a ICA Tech, como lo evidencia la solicitud de una garantía a Emica. (39-41) 
El gobierno venezolano sostuvo que Estados Unidos de América no tenía ningún interés sobre el caso que involucra a una empresa venezolana controlada por intereses mexicanos, y ningún ciudadano de Estados Unidos de América trabaja en Aucoven. Lo anterior está confirmado por la intervención diplomática de México a favor de Aucoven. (45) En suma, Venezuela no aceptó nunca que Aucoven fuese tratada como nacional de Estados Unidos de América para fines de la jurisdicción del CIADI. (47) Además, las partes acordaron que no habría jurisdicción del CIADI con base en el control de Aucoven por Emica, sino que se sometería a una arbitraje independiente en Caracas bajo las leyes venezolanas. (49) Venezuela sólo consintió al arbitraje basada en la transferencia real del control de Aucoven a un nacional de otro Estado contratante del CIADI. (50) Aunque las partes hubieran acordado que Aucoven era un nacional de Estados Unidos de América, se debe aplicar un estándar objetivo de control efectivo; así, el control mexicano de la compañía debe impedir la jurisdicción del CIADI. (52)

El gobierno mantuvo finalmente que al acceder al CIADI, se suspende la protección diplomática del nacional de una parte contratante. De modo que Aucoven no pude gozar simultáneamente de la protección diplomática de México y la jurisdicción del Tribunal del Centro (artículo 27 del convenio del CIADI). (53-55) Concluyó el Estado, argumentando que el acuerdo de las partes fue someter la disputa a un arbitraje en Venezuela. (56)

Aucoven argumentó que el Estado aceptó tratarle como nacional de un Estado parte del CIADI al autorizarse la transferencia de acciones de Aucoven a ICA Tech, y que, por lo tanto, el CIADI tiene jurisdicción sobre el caso. (57)

El acuerdo de concesión brinda jurisdicción al CIADI cuando el accionista mayoritario de Aucoven llegara a ser nacional de una parte contratante. (58) El convenio del CIADI da a las partes una gran libertad para definir qué significa control extranjero; y según el acuerdo de concesión, las partes equipararon la existencia de control extranjero a la transferencia de acciones. (63) La propiedad de acciones fue el criterio acordado para el estándar de control. (64) En consecuencia, ya que las partes llegaron a un acuerdo, el tribunal no debe examinar otros criterios; y la identidad corporativa puede sólo ser dejada de lado en casos de fraude o abuso. (65-67). 
Respecto de la intervención de México, el demandante argumentó que se trató sólo de solución amigable, y que no hubo quejas presentadas oficialmente frente al gobierno venezolano. Y aunque esto representara protección diplomática, el artículo 27 del convenio no se aplica justamente porque México no es parte de él.

El tribunal encontró inconsistencias en el argumento del demandado. De acuerdo con el contrato de concesión, la mayoría de accionistas nacionales de un miembro del CIADI implica que se tratará a Aucoven como nacional de tal país, sujetándose a la jurisdicción del centro. Especialmente, el tribunal no encontró por qué la expresión "accionistas mayoritarios del concesionario" debía interpretarse como si conteniese un estándar de control efectivo y no simplemente de accionistas mayoritarios. (87) De acuerdo con esto, la jurisdicción del Centro está sujeta a la transferencia de acciones que tuvo lugar en agosto de 1998. (91)

Por otro lado, aún cuando es importante el consentimiento a la jurisdicción del tribunal, la convención del centro adopta algunos criterios objetivos. Uno de ellos es que cuando la empresa esté incorporada en el país huésped, las partes acuerdan tratarla como extranjera por virtud del control extranjero. Este término no fue definido, y la concesión da a las partes libertad para definirlo, siempre que el acuerdo no deje de ser razonable o se aparte de la finalidad de la convención. (96-7) Mientras el acuerdo de las partes no prive al término de su sentido objetivo, éste no debe ser dejado de lado. (99)

El convenio del CIADI (art. 25.2(b)) establece dos requisitos de las compañías incorporadas localmente: a) que las partes hayan acordado tratarla como nacional de otro Estado parte, para fines de la convención; y b) que esté sujeta a control extranjero. Pero la convención deliberadamente no define el estándar de nacionalidad, según se ve en los trabajos preparatorios, por falta de acuerdo. (104-107) El criterio tradicional de nacionalidad es el lugar de incorporación, aunque el lugar de la administración central puede tomarse en cuenta. (107-108)

No obstante el empleo de este criterio en numerosos casos del CIADI, las partes pueden adoptar por acuerdo cualquier criterio que no se aparte de lo razonable. (109) Para determinar el control extranjero que exige la convención, algunos tribunales se refieren a la entidad que controla a la entidad nacional; otros se refieren incluso a la nacionalidad de la empresa que controla a la propia entidad controladora. El gobierno venezolano arguye que la convención se refiere al "control efectivo", y no 
sólo al control extranjero, pero el tribunal no encontró evidencia de ello. Para adoptar una definición de control extranjero más restrictiva que la empleada por las partes, el tribunal debió cerciorarse de que tal acuerdo no excede lo razonable o contradiga las finalidades de la Convención del CIADI. (116)

El tribunal no encontró que la personalidad corporativa de ICA Tech fuera un engaño, para cubrir el control de parte de otra corporación, vgr., Emica. Entre otras razones, el tribunal decidió que ICA Tech tenía otras funciones, además de servir de pantalla a Aucoven para acceder a la jurisdicción del CIADI. (126) Además, el gobierno de Venezuela —-decidió el tribunal- podía haber determinado las consecuencias jurisdiccionales de la transferencia de acciones, porque Aucoven le dio toda la información necesaria; por lo tanto, no hubo engaño. (128) En conclusión, el tribunal decidió que el artículo 64 del acuerdo de concesión le confiere jurisdicción. El tribunal contrastó su decisión con Banro vs. Congo, en donde no se había definido "control extranjero" en el contrato base de la demanda, ni la transferencia de acciones estaba sujeta a la autorización del gobierno.

\section{Minhlay International Corporation vs. Sri Lanka, Caso}

CIADI núm. ARB/00/2, marzo 15, 2002

El caso se sometió al tribunal bajo el Acuerdo Bilateral de Inversión entre Estados Unidos de América y Sri Lanka. La disputa versaba sobre la jurisdicción del tribunal en un caso que involucraba a una compañía canadiense y a su controladora estadounidense, no siendo Canadá.

El actor sostenía que puede traer una demanda en propio nombre y de parte de su socia Minhlay Canadá, porque puede hacerlo según las leyes de California. (13-14) El tribunal señaló que era necesario cubrir el requisito de nacionalidad según la Convención del CIADI. Sin embargo, la socia canadiense no puede ceder a la socia estadounidense un derecho mayor del que ella misma tiene. Es decir, si ella misma no puede aparecer ante el tribunal (porque Canadá no es parte de la Convención del CIADI) entonces la socia estadounidense no puede aparecer en su nombre. (23) Sin embargo, Minhlay International Corporation si puede aparecer ante el tribunal en nombre propio. (26)

Por otro lado, el actor pretendía que el gobierno era responsable por los gastos preparatorios de un proyecto para construir una planta eléctrica. La Convención del CIADI requiere que la disputa surja de una inver- 
sión. En este caso, el tribunal debió determinar si los gastos en que el actor incurrió durante la implementación de las cartas de intención entre él y el Estado, califican como una inversión. Las evidencias muestran cartas de intención, de acuerdo y de extensión para la construcción de una planta eléctrica. Sin embargo, el tribunal encontró que ninguno de estos documentos muestran una obligación contractual de parte del Estado. (48) Más aún, la exclusividad nunca llegó a ser un contrato, según lo expresaban algunas cláusulas en estos documentos. Fundamentalmente, el acuerdo entre Estados Unidos de América y Sri Lanka requiere que el Estado consienta a la inversión para que esté protegida bajo este régimen. Para acreditar el carácter de inversión, el actor argumentó que según un autor, del $2 \%$ al $4 \%$ de una inversión está integrado por los gastos preparatorios del proyecto. Es interesante que el tribunal haya hecho notar que las opiniones de expertos sobre las prácticas de empresas multinacionales no constituyen fuentes de derecho como publicistas altamente calificados. (51)

Es interesante además que el significado de "inversión", no se buscó en el acuerdo bilateral base de la demanda, sino en el tratado del CIADI y la costumbre, a diferencia del Caso de la autopista concesionada de Venezuela.

\section{TEMAS SUSTANTIVOS}

\section{Caso LaGrand (Alemania vs. Estados Unidos de América)} junio 27, 2001 CIJ núm. 104, medidas provisionales; jurisdicción; relaciones consulares

El 27 de junio, la Corte Internacional de Justicia (CIJ) emitió su fallo en el Caso LaGrand (Alemania vs. Estados Unidos de América) respecto de la Convención de Viena de Relaciones Consulares (la convención). La corte encontró que Estados Unidos de América violó el artículo 36 de la convención y que incumplió la orden de medidas provisionales que la corte emitió el 3 de marzo de 1999, por la ejecución de Karl y Walter LaGrand, de nacionalidad alemana, el 24 de febrero y el 3 de marzo de 1999, respectivamente. La corte fundó su jurisdicción en el artículo 1 del Protocolo opcional de la Convención sobre el Arreglo de Controversias (el 'Protocolo'). 
Los hechos del caso son los siguientes:(13-34) El caso involucra a dos nacionales alemanes, Karl y Walter LaGrand, que fueron condenados a muerte en 1984 por su participación en el robo de un banco en Arizona en el que murió el gerente y fue lesionado un empleado. Un hecho controvertido fue cuando las autoridades estadounidenses informaron a los hermanos LaGrand respecto de sus derechos de comunicación con el consulado alemán. (16) Los hermanos LaGrand intentaron tres procedimientos para rebatir la sentencia entre 1987 y 1992: apelación de la sentencia, un segundo procedimiento de revisión, y la solicitud de Habeas Corpus en una corte federal; todos resultaron infructuosos. En 1998 los hermanos LaGrand fueron informados de sus derechos consulares. (24) El 3 de marzo, cuatro horas antes de la ejecución de Walter LaGrand, y de acuerdo con la solicitud de Alemania, la corte emitió una orden de medidas provisionales, requiriendo a Estados Unidos de América que tomara las medidas necesarias para que LaGrand no fuera ejecutado antes de la resolución del caso. $(29,30)$

Estados Unidos de América objetó la jurisdicción de la corte respecto de tres demandas de Alemania. (35) Alemania ejerció protección diplomática por violación a los derechos de LaGrand, además de los derechos del Estado bajo el artículo 36, párrafo 1 de la Convención. La corte asumió su jurisdicción sobre las violaciones a presuntos derechos de LaGrand, desechando el argumento de Estados Unidos de América de que la protección diplomática no estaba incorporada en la convención, y era, por lo tanto, un derecho de costumbre internacional fuera del alcance del protocolo opcional. (42)

Más adelante, rechazando el argumento de que la decisión sobre la fuerza vinculatoria de las medidas provisionales emitidas era inadmisible, la corte señaló que la jurisdicción para decidir acerca de un caso implica su facultad para decidir sobre el cumplimiento de las medidas provisionales. (45) $\mathrm{Al}$ respecto citó el Caso de Pesquerías. ${ }^{48}$

Finalmente, la corte rechazó el argumento de Estados Unidos de América sobre la falta de jurisdicción de la corte para determinar si la garantía de no reiteración de la conducta ilícita era un remedio adecuado para la violación de la convención. Citando la decisión de la Fábrica de 
Chorzow, ${ }^{49}$ dijo que la jurisdicción sobre un caso implica la jurisdicción para determinar los remedios por una violación. (48)

La corte no aceptó el argumento de EUA de que al juzgar sobre cuestiones procesales penales del derecho interno de ese país, la corte se instituía como un tribunal de cuarta instancia, porque la corte aplicaría derecho internacional exclusivamente. (50) Se dijo que a pesar de la premura con la que Alemania había solicitado las medidas provisionales, la corte había decidido ordenarlas, y que Alemania estaba facultada para reclamar su cumplimiento, por lo tanto la consideración sobre el cumplimiento de las medidas provisionales fue declarada admisible. (57) Finalmente, encontró que aunque EUA objetaba la admisibilidad de la protección diplomática sobre LaGrand por no haberse agotado los recursos locales, este país no podía oponer tal objeción porque habían sido los actos de sus autoridades lo que habían impedido al sujeto el oponer su nacionalidad alemana en procedimientos legales para revisar su sentencia (vgr., Habeas Corpus). (58)

En la decisión, la corte declaro primero que EUA violó la convención por no informar rápidamente a LaGrand de sus derechos consulares. EUA admitió tal violación y ofreció disculpas a Alemania con anterioridad. Rehusándose a opinar sobre el efecto que podría haber tenido la protección consular de los hermanos LaGrand sobre sus sentencias de muerte, la corte declaró la violación a la convención en contra de los derechos de los sentenciados y del Estado alemán. (74) Además de la violación a los derechos del Estado respecto de sus nacionales inculpados, la corte coincidió con Alemania en que la convención establecía en el artículo 36 párrafo 1 , derechos individuales que podían ser reclamados a través de la protección diplomática. (78) La corte no estimó necesario pronunciarse sobre si estos derechos consulares son derechos humanos, o no.

Luego, la corte determinó que la aplicación de la regla del procedural default que impidió a los LaGrand oponer su nacionalidad alemana ante una corte federal, constituía una violación al artículo 36.1 de la convención. La corte no declaró que la regla de provisional default contraviniera la convención en cuanto tal, sino que la violación había ocurrido en este caso específico. (91)

Sobresale la declaración de la fuerza vinculatoria de las medidas provisionales. (92) Por primera vez en su historia, la Corte Mundial se pronun- 
ció sobre la fuerza de las medidas provisionales, declarándolas vinculatorias. (110) Esta conclusión fue alcanzada tras hacer una detallada interpetación de los instrumentos relevantes. Decidió la corte que en la interpretación de su estatuto, en los trabajos preparatorios del mismo, y en el artículo 94 de la Carta de Naciones Unidas nada sugería que las medidas fueran vinculatorias, y que su fuerza se derivaba del objeto y propósito del propio estatuto. Decidió además que EUA no cumplió con la orden de marzo de 1999, pero no porque LaGrand hubiera sido ejecutado, sino porque consideró que el Estado no tomó todas la medidas a su alcance para evitar la ejecución. Consideró especialmente la premura con que el procedimiento fue instituido por Alemania en 1999.

Respecto de los remedios, Alemania solicitó a la corte que ordenar a EUA dar garantías de que no volvería a ocurrir una violación del artículo 36 de la convención. Sin embargo, la corte tomó nota de los esfuerzos que el demandado declaró haber emprendido, como una garantía de que la violación no volvería a ocurrir, y le ordenó que mantuviera los medios internos de su elección disponibles para que en caso de repetirse la situación de este caso, los involucrados pudieran solicitar la revisión de la sentencia. Alemania no solicitó ningún otro remedio. (127)

\section{Caso concerniente a la orden de arresto del 11 de abril de 2000} (República Democrática del Congo vs. Bélgica) CIJ: inmunidad de ministros de relaciones exteriores; jurisdicción universal

En este caso, la CIJ se refirió por primera vez a los límites de las inmunidades de los secretarios de relaciones exteriores respecto de la jurisdicción penal. Destaca el párrafo 61 de la sentencia, en donde la corte señala cuatro circunstancias en que un ministro de relaciones exteriores puede ser sometido a la jurisdicción penal, distinguiendo entre inmunidad e impunidad. La corte no establece como una de estas circunstancias un caso de violación al derecho penal internacional por actos en la capacidad oficial del ejercicio del cargo de ministro. Esto implica que la jurisdicción universal (de ser legal en derecho internacional) no puede ejercerse en contra de un funcionario de este nivel por actos cometidos en su capacidad oficial. Conviene, sin embargo, considerar que los hechos por los que la corte fue llamada a considerar, no involucraban exactamente esta situación hipotética, y por lo tanto, cualquier conclusión sobre el peso de la 
inmunidad diplomática sobre el ejercicio de la jurisdicción universal debiera pesarse en esa luz.

La disputa se centra en los siguientes hechos. El 11 de abril de 2001 el juez belga de primera instancia emitió una orden internacional de arresto en contra del entonces ministro de asuntos exteriores de la República Democrática del Congo (RDC), Abdulaye Yerodia Ndombasi, acusándolo de violaciones graves a las convenciones de Ginebra de 1949. (13) La orden fue transmitida a las autoridades congolesas y a Interpol. En noviembre de 2000, el señor Yerodia fue nombrado ministro de educación;(18) a mediados de abril de 2001 dejó de formar parte del gobierno de la RDC. (19)

Aunque en la solicitud, el gobierno de la RDC argumentó que la legalidad de la orden de arresto dependía de $a$ ) la legalidad de la jurisdicción universal por parte de Bélgica y $b$ ) el respeto a la inmunidad de jurisdicción penal del personal diplomático, en sus argumentos orales sólo se apoyó en el segundo argumento.

El gobierno belga interpuso cuatro objeciones preliminares:

1. Ausencia de una disputa legal. Bélgica alegó que el hecho de que el señor Yerodia no fuera parte del gobierno de la RDC implicaba la ausencia de una disputa legal. Sin embargo, la corte la rechazó argumentando que en el momento de la decisión, la disputa entre las partes continuaba siendo la legalidad de la orden de arresto de 2000 y las consecuencias que se derivarían de ello. (27)

2. Ausencia de objeto de la disputa. Bélgica alegó que el hecho de que el señor Yerodia no fuera ya miembro del gobierno de la RDC implicaba que la corte sólo podría declarar el sentido del derecho hacia el futuro, y que la decisión de la corte había sido privada de objeto. La corte, sin embargo, sostiene que la disputa entre los países es la legalidad de la orden de arresto, que prevalece, y no ha sido alterada por el hecho subsecuente de la ausencia del señor Yerodia del gobierno de la RDC. (32)

3. La disputa ha sido transformada por enmiendas a la solicitud (application). Bélgica argumentó que la disputa había sido transformada desde la solicitud de juicio de la RDC por hechos subsecuentes, y que esto implicaría la inadmisibilidad de la queja. (33) La corte, sin embargo, estableció que la pregunta sometida a ella, era aún si la orden de arresto emitida y circulada por las autoridades belgas en contra de quien fungía como ministro de asuntos exteriores violaba o no el derecho internacional. Por lo anterior, la disputa era la misma desde la solicitud hasta el momento del juicio. (36) 
4. Los hechos subsecuentes a la solicitud hacen que esta sea una disputa de protección diplomática en la que no se han agotado los recursos internos. Bélgica contiende que el señor Yerodia no forme parte del gobierno de la RDC lo que implica el ejercicio de protección diplomática y que no se han agotado los recursos internos. (37) La corte subrayó, sin embargo, que la RDC no invoca los derechos personales del señor Yerodia, sino los propios por la violación a la inmunidad diplomática de sus agentes. De nuevo, al momento de la solicitud, la RDC mantenía un interés legal directo en la disputa, y esa fue la base de su acción, no los derechos personales del señor Yerodia.

Se discutió también la aplicación de la regla non ultra petitia. (41) Bélgica contiende que la jurisdicción de la corte, limitada por la petición que hagan las partes, le impide juzgar sobre la legalidad de la jurisdicción universal ejercida por Bélgica, ya que la RDC sólo contiende la violación de la inmunidad diplomática. La corte concluye que, si bien no puede juzgar en la parte operativa de la decisión sobre la legalidad de la jurisdicción universal, si puede tocar el punto en su razonamiento, de ser necesario. (43)

La corte decidió que bastaba con decidir si se había violado el derecho de inmunidad, suponiendo que Bélgica tuviera jurisdicción para emitir la orden de arresto. (46)

La ilegalidad de la orden de arresto radica, según el Congo, en la imposibilidad de emitirla en contra del personal diplomático de los gobiernos. Por su parte, Bélgica arguyó que la inmunidad del ministro de asuntos exteriores cubre sólo los actos realizados en su capacidad oficial, pero no sus actos como particular. (49) Además, que el señor Yerodia no gozaba de inmunidad al cometer los actos de los que se le acusa.

La corte estableció el rationale de la regla de inmunidad diplomática, i. e. que las funciones oficiales del personal diplomático no sean obstaculizadas por la acción de la autoridad de gobiernos extranjeros. (53-4) Además aclaró que no podía distinguirse entre inmunidad sobre actos oficiales y actos privados, porque cualquiera que hubiera sido la razón, el ejercicio de la jurisdicción penal sobre el ministro de asuntos exteriores claramente le impedía el cumplimiento de sus funciones oficiales. (55)

El segundo argumento de Bélgica fue que los crímenes internacionales constituyen una excepción a la regla de la inmunidad. (56) Como evidencia ofreció los casos de Pinochet y Qadafi en el Reino Unido. Sin embargo: 
La Corte ha examinado cuidadosamente la práctica estatal, incluyendo legislación nacional y las pocas decisiones de cortes nacionales superiores, como la Casa de los Lores y la Corte Francesa de Casación. Le ha sido imposible deducir de esta práctica que exista en derecho consuetudinario internacional cualquier forma de excepción a la regla que otorga inmunidad de jurisdicción penal e inviolabilidad a Ministros de Asuntos Exteriores, cuando se sospecha que han cometido crímenes de guerra o crímenes contra la humanidad.

La decisión de la corte no implica impunidad para quienes gozan de inmunidad: la inmunidad es un asunto procesal mientras que la responsabilidad penal es sustantiva:(60)

Siempre y cuando tenga jurisdicción bajo derecho internacional, una corte estatal puede juzgar a un Ministro de Asuntos Exteriores de otro Estado respecto de actos cometidos antes o subsecuentemente a su periodo de servicio, así como respecto de actos cometidos durante ese periodo en sus facultades privadas $(61)$.

Finalmente, en una decisión de 13 a favor y tres en contra, la corte declaró que la emisión de la orden de arresto violaba la inmunidad diplomática del ministro,(70) así como su circulación. (71) Respondiendo a la petición de la RDC(72) la corte ordenó la cancelación de la orden(76) en una decisión dividida de 10 votos a favor y seis en contra.

Destaca la opinión separada conjunta de los jueces Higgins, Kooijmans y Burgenthal. En ella se discute y se concluye la permisibilidad (y no la obligatoriedad) del ejercicio de la jurisdicción universal. (52) Además,(89) se rechaza el dispositif de la corte que ordena la cancelación de la orden de arresto con base en que este no es un caso de violación internacional continuada, simplemente porque el señor Yerodia ya no es ministro de asuntos exteriores de la RDC. Por esto la cancelación no constituye una restitutio in integrum del status quo ante, porque ello es imposible.

La decisión de la corte puede traer como consecuencia que se abandone el caso en las cortes belgas contra Ariel Sharon, primer ministro de Israel. 50 


\section{Armando Olguín vs. República del Paraguay, Caso}

CIADI núm. ARB/98/5 Washington D. C. julio 26, 2001:

expropiación por quiebra de entidad financiera

Esta disputa se da en el marco del Convenio sobre Promoción y Protección recíproca de las Inversiones entre Perú y Paraguay (CBI). En esta decisión resaltan las consideraciones sobre los efectos de la doble nacionalidad del actor, y la naturaleza de su nacionalidad efectiva; así como la exploración del nexo causal entre los daños sufridos y el acto de gobierno reclamado.

La objeción preliminar de Paraguay radica en la inaplicabilidad del CBI a las inversiones del señor Olguín por contar con las nacionalidades peruana y estadounidense. El argumento de Paraguay se refirió a las condiciones, como la residencia, para el ejercicio de ciertos derechos. El tribunal rechazó la objeción de Paraguay con el argumento de que las condiciones que un país imponga a sus nacionales para el ejercicio de ciertos derechos, vgr., condiciones de residencia, es una cuestión de derecho interno. Para el tribunal fue suficiente establecer que ambas nacionalidades del actor eran efectivas, para decidir que el CBI era aplicable para proteger sus inversiones.

Cabe señalar que el tribunal no examinó cuál de las dos nacionalidades era efectiva, sino que aseveró que ambas nacionalidades lo eran. En la sentencia no se discute en qué sentido debieran entenderse como efectivas tales nacionalidades, ni los hechos que el tribunal empleó para tomar su decisión. Es prudente recordar que en los casos de nacionalidad efectiva, notablemente el Nottebohm ${ }^{51}$ frente a la Corte Internacional de Justicia, se separó por un lado el concepto de nacionalidad para fines de derecho interno, como hizo el tribunal arbitral en esta decisión; y por otro, los efectos oponibles a otros Estados bajo este vínculo de nacionalidad. Resulta interesante que el tribunal haya mencionado que "no ha habido controversia en cuanto a que el Señor Olguín tiene las dos nacionalidades y que ambas son efectivas". (61) Podría, sin embargo, pensarse que el concepto de nacionalidad efectiva justamente determina la relación de un nacional con un Estado en particular. Esto se aprecia en los casos en donde el individuo es nacional de las dos partes de la controversia, y la nacionalidad efectiva se emplea para determinar con cuál de los dos Estados se 
establece el vínculo dominante..$^{52}$ Pensando en esta función del concepto de nacionalidad efectiva, resulta desconcertante la decisión del tribunal de declarar que no existe controversia sobre la efectividad de la nacionalidad de ambos países. En todo caso, debe decirse también que el argumento de Paraguay, según fue reproducido en la sentencia, no se dirigió a la efectividad de la nacionalidad peruana del señor Olguín, sino a la ausencia de la condición de residente, como requisito para ejercer los derechos del CBI. Quizá si el argumento del demandado hubiera sido dirigido en otro sentido, el tribunal habría evaluado la efectividad de la nacionalidad peruana.

La disputa se refiere a las inversiones que hizo el señor Olguín en una entidad financiera: La Mercantil. El señor Olguín fue informado por el señor Olieli, del Banco Central del Paraguay, de los intereses que La Mercantil proporcionaba. $(45,47)$ A partir de 1993, el actor hizo depósitos en La Mercantil hasta por 1.25 millones de guaraníes (Gs), y recibió títulos de inversión que fueron renovados periódicamente. Hasta julio de 1995, contaba con siete títulos. Los seis últimos fueron rubricados por un funcionario del Banco Central. En total, los títulos respaldaban 2 mil 407 millones de Gs. A los seis títulos rubricados por el funcionario del Banco Central, se les hizo un abono de 48 mil Gs en 1996. El dinero sería empleado para invertir en una compañía procesadora de alimentos Súper Snacks de Paraguay. Esta compañía fue fundada en 1994, siendo Olseli vicepresidente. (51-2) La compañía costaría mil 425 millones de Gs, y sólo un tercio sería financiado con dinero propio.

En medio de una fuerte crisis económica en Paraguay, en julio de 1885, La Mercantil cerró operaciones y dejó de honrar los pagos de los títulos de inversión. (55) Una ley emitida inmediatamente después, dispuso que el gobierno se haría cargo de los activos y pasivos de la entidad hasta su liquidación, y proporcionaría ayuda financiera para el pago a depositantes en cuentas de ahorro, deduciendo el encaje legal. (57) En diciembre de ese año, otra ley dispuso que se pagaría a depositantes registrados, hasta 100 salarios mínimos mensuales por cuenta. (58)

El inversionista reclamó el pago de las cantidades depositadas en La Mercantil y no devueltas, argumentando: $a$ ) que los títulos fueron avalados por el Banco Central; $b$ ) que la negligencia del Estado en supervisar 
las actividades de La Mercantil llevó al cierre de sus operaciones; c) que los actos del gobierno fuero discriminatorios; y $d$ ) que estos actos equivalen a expropiación. (64)

El tribunal no aceptó ninguno de los argumentos del actor. Primero, expresó que para que la rúbrica en los títulos de inversión fuera considerada una garantía, sería necesario que existiera una norma paraguaya que lo indicara, cuya existencia no se demostró. Además, que aunque las actividades de vigilancia del gobierno pudieron haber sido negligentes, Olguín decidió por sí esta inversión. El argumento del carácter discriminatorio de las medidas se desechó por no haberse demostrado que el gobierno pagó la deuda a algún otro inversionista, excluyendo al señor Olguín. Tampoco fue posible para el tribunal comprender cómo esta situación puede equipararse con una expropiación.

El método del tribunal fue establecer primero si había habido omisiones de parte del gobierno en sus labores de vigilancia sobre La Mercantil; y en seguida, si había un nexo causal entre estas omisiones y la pérdida del señor Olguín. Las partes están de acuerdo, y el tribunal está convencido de que en algún grado el cierre de La Mercantil fue causado por las conductas irregulares de los gestores; que podrían haber sido detectadas y sancionadas.

Luego de examinar algunas instancias de omisiones en la vigilancia sobre las actividades de La Mercantil, (75-82) el tribunal volvió a considerar el asunto de una posible expropiación indirecta, como alegó el actor. Cabe anotar que el tribunal se refirió a un concepto de expropiación que involucra un actuar teológico, encaminado a la transferencia de propiedad sobre el bien o sus frutos, sin que una omisión pueda formar parte de este concepto. (84) Existe evidencia en derecho internacional para asegurar que ninguna de estas condiciones es necesaria para que haya una expropiación, puede tratarse de actos u omisiones que tengan el efecto de inutilizar la propiedad a tal grado que la medida sea análoga a una expropiación, aún cuando el título de propiedad no se transfiera. ${ }^{53}$ Podría decirse, además, que en realidad bastaba con que el tribunal examinara la ausencia de un nexo causal entre los actos u omisiones del Estado y las pérdidas del actor, como ya había hecho. 
En todo caso, el tribunal rechazó los argumentos del actor, pero no lo condenó a pagar los gastos en que el gobierno incurrió por el procedimiento, considerando las omisiones en la labor de vigilancia en que incurrió.

El tribunal mantuvo ese año una actividad reducida. Sólo se presentó la orden para eliminar un caso de la lista de la corte, en virtud del cumplimiento de las pretensiones del actor; y la emisión de medidas provisionales respecto de la construcción de una planta que maneja residuos nucleares.

En el desarrollo de la aplicación del TLCAN este año, destacan la interpretación del artículo 1105, y sus consecuencias sobre la interpretación del derecho consuetudinario sobre el estándar mínimo del trato a extranjeros. Es relevante también el efecto de la decisión de Metalcald, de 2001, sobre la conveniencia de Canadá como lugar para celebrar los arbitrajes del TLCAN, y las facultades de los árbitros para autorizar la intervención de terceros en los procedimientos.

\section{El TLCAN y el estándar mínimo de trato a extranjeros}

- Comisión de libre Comercio del TLCAN, nota interpretativa de ciertas normas del capítulo 11, julio 31, 2001;

- Methanex Corp. vs. Estados Unidos de América, segunda opinión del profesor sir Robert Jennings, septiembre 6, 2001;

- United Mexican States vs. Metalcald Corp, Supplementary Reasons for Judgement, octubre 2001, BCSC Vancouver, Canadá;

- Pope \& Talbot Inc. vs. Canadá CIADI, Caso núm. ARB(AF) (daños) abril 31, 2002

Quizá el desarrollo más importante en la aplicación del TLCAN en este periodo fue la interpretación de la Comisión de Libre Comercio del contenido del artículo 1105 del tratado. Este artículo se refiere al trato justo y equitativo que debe prestarse a la propiedad de extranjeros en el país huésped.

En la decisión de fondo, en el Caso de Pope \& Talbott vs. Canadá (abril 10, 2001), el tribunal arbitral decidió que este artículo incluye un trato superior al estándar mínimo internacional debido a los extranjeros en el país huésped. Contrariamente a esta decisión, en la resolución de la Suprema Corte de British Columbia en la ejecución de la sentencia de Metalclad $^{54}$ el juez dijo que el estándar de cumplimiento del artículo 1105

54 United Mexican States vs. Metalcald Corporation, Reasons for Judgement, 64-8, May 2, 2001, 2001 BCSC 664 L002904 Vancouver, Canadá. 
es el derecho de costumbre internacional, y que las partes no reflejaron en el lenguaje del tratado la intención de elevar tal nivel de trato.

El 31 de julio de 2001, la Comisión del TLCAN emitió una nota interpretativa aclarando la postura de los gobiernos sobre el tema. ${ }^{55}$ Esta nota aclara que no existe un deber general de confidencialidad sobre los documentos de los procedimientos arbitrales, a menos que la información esté protegida por la confidencialidad en los negocios, bajo el derecho interno de las partes, o según las reglas de arbitraje aplicables. Sobre el contenido del artículo 1105, aclaró que la posición de los Estados es que se incorpora el estándar consuetudinario de trato a extranjeros; que el trato justo y equitativo, y la total protección y seguridad a que se refiere el artículo no van más allá del derecho consuetudinario; y que la violación de una regla del TLCAN no implica necesariamente la violación del artículo $1105 .{ }^{56}$

Al respecto, sir Robert Jennings, en una opinión sobre el Caso de Methanex Corporation, ${ }^{57}$ hizo fuertes comentarios sobre la actitud de la comisión. Primero, explicó que el artículo 1105 no versa sobre el estándar de trato a extranjeros, sino sobre las inversiones en el territorio de las partes; ni tampoco trata sobre el derecho de costumbre. Aclaró que las facultades de la comisión son de interpretación, y no de cambios al TLCAN, y en virtud del limitado contenido del artículo 1105, les aclaró que la comisión, más que interpretarlo, reformó el contenido del tratado. El efecto de esto es que aunque la interpretación de la comisión sería normalmente obligatoria para el tribunal, la interpretación excesiva no es vinculatoria sobre el tribunal. Mencionó que la intervención de la comisión parecía más bien la intención de una de las partes por ejercer presión sobre el tribunal.

En virtud de que el Caso Pope \& Talbott vs. Canadá no estaba concluido, las consecuencias de estos actos se apreciaron en la decisión sobre daños en el caso mencionado. ${ }^{58}$ El tribunal debía determinar los daños que el demandado debía pagar a partir de un incidente de revisión en la

55 NAFTA Free Trade Commission, Note of Interpretation of Certain Chapter 11 Provisions, July 312001 .

56 Esta última aclaración parece referida a la decisión arbitral en el Caso de Metalclad en donde al violarse la obligación de transparencia, parte de los principios del tratado, el panel resolvió que el artículo 1105 había sido violado. Esto llevó al juez en British Columbia, supra nota 54, a discrepar con la posición del Pope \& Talbott.

57 Methanex Corporation vs. Unites States, Second Opinion of Professor Sir Robert Jennings, September 6th., 2001.

58 Pope \& Talbot Inc. vs. Canada CIADI Caso núm. ARB(AF) abril 31, 2002. 
propiedad del actor. Para ello, era necesario que estableciera primero, si la interpretación del artículo 1105 entra dentro del ámbito de la interpretación de tratados, y es vinculatoria para el tribunal.

Para interpretar el capítulo 11, fue necesario para el tribunal indagar sobre los trabajos preparatorios, cuya existencia no reconocían en un principio ni Canadá ni Estados Unidos de América, pero a los que México se refirió en el Caso de Methanex. (25) Luego de varios incidentes, el gobierno de Canadá mostró un expediente de 1500 páginas sobre los trabajos preparatorios que muestran sucesivas redacciones del artículo 1105 . En ninguna de ellas aparece la expresión "derecho consuetudinario". (43) Si la interpretación de la Comisión excede o no los límites de sus facultades, y es por ende obligatoria para el tribunal, no debe discutirse porque tal interpretación no puede ser aplicada retroactivamente al caso en cuestión. (47)

Sólo habría la necesidad de resolver el punto anterior si el tribunal hubiera actuado en modo contradictorio con la interpretación de la comisión, $i$. e. si hubiera aplicado un estándar más alto efectivamente que el contenido en el derecho consuetudinario. (55) Para esto, se necesitaría que el trato justo y equitativo del artículo 1105 fuera diferente que en la costumbre.

Canadá argumentó que el contenido de la costumbre sobre trato a extranjeros está expresada en la decisión del Caso Neer. ${ }^{59}$ Sin embargo, el tribunal encontró que la costumbre cambió. El tribunal determinó el contenido de la costumbre internacional citando el borrador de la Convención de la OCDE sobre la protección de propiedad extranjera, y mencionó la existencia de unos 1800 tratados bilaterales de inversión. (60-2) Estableció el tribunal que el contenido del derecho de costumbre del Caso Neer debe rechazarse en virtud de los progresos en la práctica estatal. No obstante, decidió que aún bajo el estándar del Caso Neer, los actos de Canadá constituyen una violación del estándar internacional, y por lo tanto ordenó el pago de daños por las pérdidas en que incurrió el actor. (67-9) En este caso, independientemente de la decisión final, es relevante el modo en que el tribunal examinó el contenido del estándar mínimo de trato a extranjeros, basándose principalmente en la existencia de tratados bila-

59 Neer Claim (US vs. Mexico) US-Mexico General Claims Commission, 4 RIAA 60 (1926), p. 507. En el caso se adopta un estándar de incumplimiento del deber involuntario, mala fe, o insuficiencia de acción gubernamental, tan lejos de los estándares internacionales que cualquier "hombre razonable e imparcial" reconocería. 
terales de inversión. Es prudente tener en cuenta que antes se ha cuestionado el valor de tratados bilaterales para la formación de costumbre, por considerar que aunque evidencian práctica estatal, no necesariamente reflejan la convicción de la existencia de una norma independiente del tratado. ${ }^{60}$

Otra consecuencia posible de la interpretación de la comisión, es la remisión del Caso Metalclad al tribunal arbitral, de parte de la Corte Suprema de British Columbia. En octubre de 2001, la corte emitió razones adicionales de la sentencia de mayo de 2001. ${ }^{61}$ Entonces, los daños fundados en la violación a la obligación de transparencia, que llevaron a la declaración de la violación del artículo 1105, no fueron admitidos por el tribunal. En el nuevo documento, la corte remitió la decisión al tribunal arbitral para discutir el papel de la obligación de transparencia. Es muy probable que en la nueva evaluación del caso, el tribunal arbitral discuta la relación que guarda su decisión anterior con la interpretación de la comisión.

- Caso de la Comunidad Mayagna (Sumo) Awas Tingni vs. Nicaragua Corte IDH serie C núm. 70, sentencia de agosto 31, 2001

- Caso Las Palmeras (Colombia) Corte IDH serie C núm. 90, sentencia de diciembre 6, 2001

\section{REPARACIONES}

- Caso Baruch Ivcher Bronstein vs. Perú, Corte IDH serie C núm. 84 (Interpretación de la sentencia de fondo) Sentencia de septiembre 4, 2001

- Caso Barrios Altos. Chumbi Puma y otros vs. Perú, Corte IDH serie $C$ núm. 83 (interpretación de la sentencia de fondo) sentencia de septiembre 3, 2001

- Caso Barrios Altos (Chumbi Puma, Aguirre y otros vs. Perú) Corte IDH serie C. núm. 87 (reparaciones) Sentencia de noviembre 30, 2001

61 United Mexican States vs. Metalcald Corporation, Supplementary Reasons for Judgement, octubre 2001, 2001 BCSC Vancouver, Canadá. 
- Caso Gustavo Cesti Hurtado vs. Perú, Corte IDH serie C núm. 86 (interpretación de la sentencia de fondo) Sentencia de noviembre 27, 2001

- Caso Cantoral Benavides vs. Perú, Corte IDH serie C núm. 88 (reparaciones) Sentencia de diciembre 3, 2001

\section{PRÁCTICA MEXICANA}

El 9 de abril de 2002 se publicó el informe del relator especial sobre la independencia de jueces y abogados, Dato'Param Coomaraswamy, sobre la situación en México. El texto presentado en la Comisión de Derechos Humanos de Naciones Unidas describe y evalúa la práctica nacional según los estándares internacionales pertinentes. Quisiera dirigir la atención a la aplicación del derecho internacional de los derechos humanos. Dada la necesidad del empleo de normas internacionales en las cortes, sobresale la aserción del relator acerca de que la tesis de 2000 de la SCJ sobre tratados internacionales, podría permitir su aplicación aún en contra de la Constitución. ${ }^{62}$ Sin embargo, hay preocupación por el desconocimiento de los jueces del derecho internacional y de las normas de derechos humanos. ${ }^{63}$ Aunado a esto, no existen de manera generalizada programas obligatorios de derecho internacional público y derechos humanos en las escuelas de derecho. ${ }^{64}$

\section{CONCLUSIONES}

Del desarrollo de la jurisdicción internacional en los foros aquí revisados, puede verse el desarrollo de la nacionalidad de las demandas, la jurisdicción de los tribunales, el alcance de las medidas provisionales, las normas de interpretación de tratados y la determinación del contenido de la costumbre. No se encuentran discrepancias significativas, aunque algunas sentencias son más ricas que otras en el modo de contextualizar las decisiones en el marco del derecho internacional existente. Destaca de

62 Informe del relator especial sobre la independencia de los magistrados y abogados, señor Dato'Param Coomaraswamy presentado de conformidad con la resolución 2001/39 de la Comisión de Derechos Humanos ECOSOC E/CN.4/2002/72/Add.1 24 de enero de 2002, http://www.cinu.org.mx/biblioteca/documentos/dh/G0210345.doc (32).

63 Ibidem (59).

64 Ibidem (101). 
modo especial la resolución del Caso de la Fundación Allende vs. Chile, en donde una gran diversidad de casos respecto de medidas provisionales de la Corte Internacional de Justicia son citados por el tribunal. Igualmente, el tribunal, en el Caso de la autopista concesionada de Venezuela, se refirió a la sentencia del Caso Barcelona Traction. Es justo decir que los tribunales no se mantienen ajenos a la evolución del derecho internacional, y se refieren en general a sentencias previas de tribunales similares, pero de modo importante, se refieren también a las resoluciones de la Corte Internacional de Justicia. Lo anterior muestra que en este año, la posición de la Corte Mundial en el contexto de la proliferación de foros jurisdiccionales no es del todo débil, y que sus decisiones son consideradas como relevantes. En todo caso, debe considerarse la opinión del presidente de la Corte Mundial sobre la posibilidad de que los tribunales internacionales mantengan una relación más fuerte con ésta.

Guadalupe BARRENA* 